\title{
Separating the effects of climate and vegetation on evapotranspiration along a successional chronosequence in the southeastern U.S.
}

\section{Authors: Stoy, Paul C., Gabriel G. Katul, Mario B. S. Siqueira, Jehn-Yih Juang, Kimberly A. Novick, Heather R. McCarthy, A. Christopher Oishi, Joshua M. Uebelherr, Hyun-Seok Kim, and Ram Oren}

This is the peer reviewed version of the following article: see citation below, which has been published in final form at https://doi.org/10.1111/j.1365-2486.2006.01244.x. This article may be used for non-commercial purposes in accordance with Wiley Terms and Conditions for SelfArchiving.

Stoy, Paul C., Gabriel G. Katul, Mario B. S. Siqueira, Jehn-Yih Juang, Kimberly A. Novick, Heather R. McCarthy, A. Christopher Oishi, Joshua M. Uebelherr, Hyun-Seok Kim, and Ram Oren (2006) Separating the effects of climate and vegetation on evapotranspiration along a successional chronosequence in the southeastern U.S. Global Change Biology 12: 2115-2135. DOI: 10.1111/j.1365-2486.2006.01244.x. 


\title{
Separating the effects of climate and vegetation on evapotranspiration along a successional chronosequence in the southeastern US
}

\author{
PAUL C. STOY, GA BRIEL G. KATUL, MARIO B. S. SIQUEIRA, JEHN-YIH JUANG, \\ KIMBERLY A. NOVICK, HEATHER R. M CCARTHY, A. CHRISTOPHER OISHI, \\ JOSHUA M. UEBELHERR, HYUN-SEOK KIM and RAM OREN \\ Nicholas School of the Environment and Earth Sciences, Duke University, Box 90328, Durham, NC 27707-0328, USA
}

\begin{abstract}
We combined Eddy-covariance measurements with a linear perturbation analysis to isolate the relative contribution of physical and biological drivers on evapotranspiration (ET) in three ecosystems representing two end-members and an intermediate stage of a successional gradient in the southeastern US (SE). The study ecosystems, an abandoned agricultural field [old field (OF)], an early successional planted pine forest (PP), and a late-successional hardwood forest (HW), exhibited differential sensitivity to the wide range of climatic and hydrologic conditions encountered over the 4-year measurement period, which included mild and severe droughts and an ice storm. ET and modeled transpiration differed by as much as 190 and $270 \mathrm{~mm} \mathrm{yr}^{-1}$, respectively, between years for a given ecosystem. Soil water supply, rather than atmospheric demand, was the principal external driver of interannual ET differences. ET at OF was sensitive to climatic variability, and results showed that decreased leaf area index $(L)$ under mild and severe drought conditions reduced growing season (GS) ET ( $\mathrm{ET}_{\mathrm{GS}}$ ) by ca. $80 \mathrm{~mm}$ compared with a year with normal precipitation. Under wet conditions, higher intrinsic stomatal conductance $\left(g_{\mathrm{s}}\right)$ increased $\mathrm{ET}_{\mathrm{GS}}$ by $50 \mathrm{~mm}$. ET at PP was generally larger than the other ecosystems and was highly sensitive to climate; a $50 \mathrm{~mm}$ decrease in $\mathrm{ET}_{\mathrm{GS}}$ due to the loss of $L$ from an ice storm equaled the increase in ET from high precipitation during a wet year. In contrast, ET at HW was relatively insensitive to climatic variability. Results suggest that recent management trends toward increasing the land-cover area of PP-type ecosystems in the SE may increase the sensitivity of ET to climatic variability.
\end{abstract}

Keywords: Eddy covariance, evapotranspiration, oak-hickory forest, old field, Pinus taeda

Received 28 November 2005; revised version received 5 June 2006 and accepted 11 June 2006

\section{Introduction}

Evapotranspiration (ET) is controlled by external (i.e. physical, climactic) and internal (i.e. biological) drivers, both of which are projected to change on multiple spatial and temporal scales due to the coupled effects of climate change and anthropogenic ecosystem management (Pielke et al., 1998; Houghton et al., 2001; Wear \& Greis, 2002; Foley et al., 2003). Thus, understanding the relative roles of climate vs. vegetation on ET is critical for predicting how water cycling will respond to future physical and biological perturbations, espe- cially as predictions of vegetative and climatic changes, including extreme events, become more spatially and temporally refined (Houghton et al., 2001; Wear \& Greis, 2002; Katz et al., 2005). For example, predictive skill will increase with improved understanding of the mechanisms responsible for hurricanes (Xie et al., 2002, 2005) and ice storms (Ramos da Silva et al., 2006), and the El Niño events (Hoerling \& Kumar, 2003) that are associated with summer drought in the southeastern US (SE, Peters et al., 2003). Studies are now exploring the implications of these exogenous events on the differential loss of productivity within various SE ecosystems (McNulty, 2002; McCarthy et al., 2006); however, their impact on the differential changes in water cycling in general and ET in particular has received much less attention, the subject of this work. 
The objective of this study is to isolate the contribution of vegetation from that of climate and soils on controlling ET at three adjacent SE Piedmont ecosystems. We measured ET using the Eddy-covariance (EC) technique for 4 years at old field (OF), early successional planted pine forest (PP), and late-successional oak-hickory forest (HW) ecosystems (Fig. 1). These ecosystems represent a typical postagricultural successionary sequence in the SE, are adjacent with towers sufficiently separated such that their flux footprints rarely overlap, and experience similar climatic and edaphic conditions. Thus, any interecosystem differences in ET in response to common external drivers can be attributed to the effects of vegetation rather than climate and soils. Furthermore, a common shallow rooting depth of ca. $35 \mathrm{~cm}$ ensures that ET is controlled by the recent precipitation $(P)$ signal without confounding effects from groundwater.

The study ecosystem types are common on the landscape, but land cover is rapidly changing. For example, over the next 40 years, the area of land in pine plantation in the SE is projected to increase from 0.13 to
0.22 million $\mathrm{km}^{2}$, with concomitant declines in upland hardwood forested area from 0.27 to 0.23 million $\mathrm{km}^{2}$ and agricultural land from 0.40 to 0.26 million $\mathrm{km}^{2}$ (Wear \& Greis, 2002). If ET in these three vegetation types shows distinctly different rates and responses to climatic forcing, such a dramatic change in vegetation cover could substantially impact surface fluxes and water cycling across the SE, including the triggers of convective rainfall (Juang et al., 2006).

In a first-order analysis, ET might be considered a conservative quantity (Roberts, 1983; Gholz and Clark, 2002), especially in wet temperate climates if it is limited by energy availability irrespective of ecosystem type. For example, Gholz and Clark (2002) found that ET was controlled by climate rather than ecosystem type along a chronosequence of slash pine ( $P$. elliottii Englm.); net radiation $\left(R_{\mathrm{n}}\right)$ explained more than $80 \%$ of the variability in LE. However, one might also expect to find some modulations in ET and especially its component fluxes - transpiration $(T)$ and evaporation $(E)$ - due to soil-plant hydraulics. In particular, $T$ should vary among ecosystems comprised of different species with

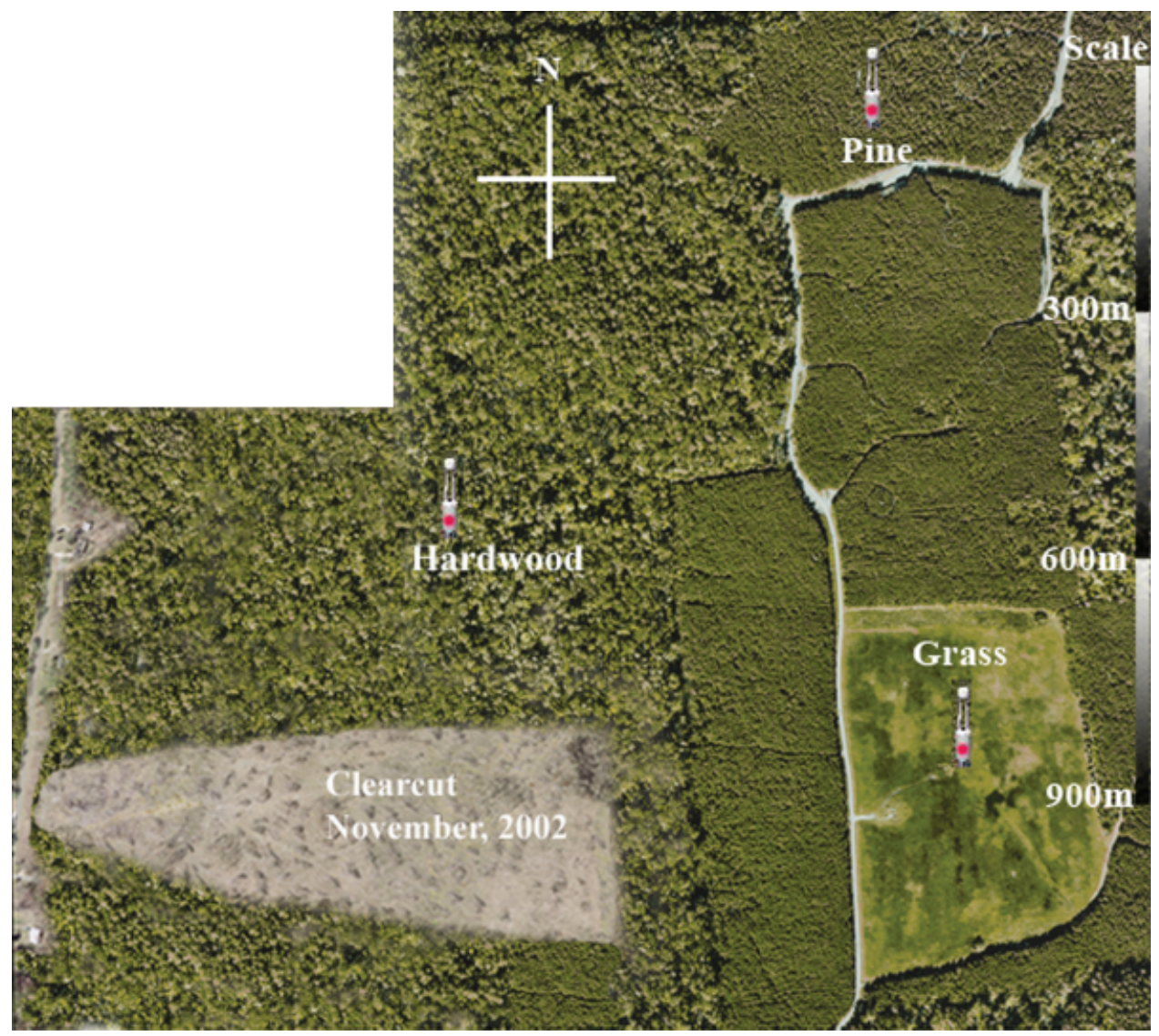

Fig. 1 A color-inverted infrared aerial photograph of the three study ecosystems in the Blackwood Divison of Duke Forest near Durham, NC. Measurement towers are separated by less than $800 \mathrm{~m}$. The clearcut to the south of HW lies on private land. Fluxes dominated by the signature of the clearcut are excluded from this analysis. 
differences in drought sensitivitiy and canopy morphology (Lai \& Katul, 2000; Oren \& Pataki, 2001; Pataki \& Oren, 2003) in response to available water, radiation, and vapor pressure deficit (i.e. atmospheric coupling, Jarvis \& McNaughton, 1986, but see Roberts, 1983). However, the magnitudes of these responses over long terms are unknown.

We address the study objective in two ways. First, we quantify the influence of vegetation on the hydrologic and energy budgets, focusing on net differences in ET in response to mild and severe droughts, a wet year following an ice storm and a year with normal precipitation. Next, we analyze interecosystem sensitivity to the specific mechanisms responsible for variability in ET at the growing season (GS) time scale $\left(\mathrm{ET}_{\mathrm{GS}}\right.$, see Table 1 for abbreviations). We show that $\mathrm{ET}_{\mathrm{GS}}$ is a linear function of the product of the physical drivers $P$ and vapor pressure deficit $(D)$, and the biological drivers leaf area index $(L)$, and intrinsic stomatal conductance $\left(g_{\mathrm{s}}\right)$. Thus, we can assess the sensitivity of the ecosystems to these drivers through a linear perturbation analysis, which we discuss after presenting the experimental setup and GS and annual sums of ET and its components. We finish by discussing some broader implications of the experimental findings on water resources in the SE.

\section{Materials and methods}

\section{Site description}

EC measurements of ET and associated environmental drivers were collected from 2001 through 2004 at OF, PP and HW ecosystems in the Blackwood Division of the Duke Forest near Durham, NC $\left(35^{\circ} 58^{\prime} 41.430^{\prime \prime} \mathrm{N}\right.$, $79^{\circ} 05^{\prime} 39.087^{\prime \prime} \mathrm{W}, 163 \mathrm{~m}$ a.s.l. - see Fig. 1 ). The three study ecosystems model a typical SE ecological succession from OF to PP to HW (Oosting, 1942), and represent dominant ecosystem types in the SE. The ecosystems lie adjacent to one another on Enon silt loam, a low fertility Hapludalf typical of the SE US Piedmont, with a transition to Iredell gravelly loam toward HW and the northern part of OF (Pataki \& Oren, 2003). EC measurement towers lie within $800 \mathrm{~m}$ of each other (Fig. 1). An impervious clay pan underlies the research sites at ca. $35 \mathrm{~cm}$ belowground (Oren et al., 1998; Lai \& Katul, 2000) thereby imposing similar constraints on root-water access for all three ecosystems. Long-term mean annual $T_{\mathrm{a}}$ and $P$ are $15.5^{\circ} \mathrm{C}$ and $1145 \mathrm{~mm}$, respectively.

Detailed characteristics of the ecosystems can be found elsewhere (Ellsworth et al., 1995; Oren et al., 1998; Lai \& Katul, 2000; Pataki \& Oren, 2003; Novick et al., 2004; Stoy et al., 2005). We briefly describe each for completeness. OF is approximately $480 \mathrm{~m} \times 305 \mathrm{~m}$ and was established after a burn in 1979. It is mowed at least once annually during the summer for hay and to check woody encroachment (Novick et al., 2004). The vegetation is dominated by the $\mathrm{C}_{3}$ grass Festuca arundinaria Shreb., with minor forb and other $C_{3}$ and $C_{4}$ grass species including Lespedeza cuneata (Dum. Cours.) G. Don, Andropogon virginicus L., and Sorghum halepense (L.) Pers. Canopy height $(h)$ is spatially and temporally variable and averages ca. $0.1-1 \mathrm{~m}$ depending on harvest and GS. EC instrumentation is at $2.8 \mathrm{~m}$ on a $6 \mathrm{~m}$ tall tower (Table 2).

PP was established in 1983 following a clear cut and a burn. Pinus taeda L. (loblolly pine) seedlings were planted at $2.4 \mathrm{~m} \times 2.4 \mathrm{~m}$ spacing and ecosystem development has not been managed after planting. $h$ increased from $16 \mathrm{~m}$ in 2001 to $18 \mathrm{~m}$ in 2004. The canopy is comprised primarily of $P$. taeda with some emergent Liquidambar styraciflua $\mathrm{L}$. and a diverse and growing understory with 26 different woody species of diameter breast height $>2.5 \mathrm{~cm}$. The flux tower lies upwind of the $\mathrm{CO}_{2}$-enriched components of the free atmosphere carbon enrichment (FACE) facility (Hendrey et al., 1999) located in the same pine forest. EC instrumentation is at $20.2 \mathrm{~m}$ (Table 2 ) on a $22 \mathrm{~m}$ tower.

HW is classified as an uneven-aged (80-100-year old) oak (Quercus) - hickory (Carya) forest with L. styraciflua and Liriodendron tulipifera L. also contributing to the canopy and a diverse understory with similar species as PP. The ecosystem has not been managed after establishment. $h$ averaged $25 \mathrm{~m}$ with some emergent treetops reaching over $35 \mathrm{~m}$, and the canopy has large and frequent gaps. EC instrumentation is at $39.8 \mathrm{~m}$ on a $42 \mathrm{~m}$ tall tower (Table 2). There was an 11.9 ha clearcut in HW $200 \mathrm{~m}$ south of the measurement tower on private land adjacent to the Duke Forest in November 2002 (Fig. 1). We minimize the effects of this disturbance as described in the "Data Filtering" section below.

\section{Measurements}

We measured and modeled the components of the energy balance at half-hourly time scales for 4 years at the three study ecosystems:

$$
R_{\mathrm{n}}-\mathrm{LE}-H-G-M=I,
$$

with a focus on latent heat flux (LE), where $H$ is sensible heat exchange, $G$ is energy storage below the canopy (predominantly in soil) and is near 0 when averaged for $24 \mathrm{~h}$ periods, and $M$ accounts for photosynthesis and plant metabolism and is assumed to be trivial, ca. 0.1-0.4\% under field conditions (Odum, 1971). The imbalance $(I)$ often arises because of scale issues in measurements, advective energy transport, and the fact that the finite sampling duration and frequency in EC 
Table 1 List of abbreviations with units and definitions

\begin{tabular}{|c|c|c|}
\hline Abbreviation & Units & Definition \\
\hline$a$ & $\mathrm{~m} \mathrm{~s}^{-2}$ & Gravitational acceleration \\
\hline$A_{\mathrm{n}}$ & $\mu \mathrm{mol} \mathrm{m}{ }^{-2} \mathrm{~s}^{-1}$ & Net photosynthesis \\
\hline$b$ & & Scale parameter of the Laplacian distribution \\
\hline$C_{\mathrm{a}}$ & ppm & Atmospheric $\mathrm{CO}_{2}$ concentration \\
\hline$C_{\mathrm{d}}$ & & Canopy drag coefficient \\
\hline$C_{\mathrm{i}}$ & ppm & Leaf-internal $\mathrm{CO}_{2}$ \\
\hline$c_{p}$ & $\mathrm{~J} \mathrm{~mol}^{-1} \mathrm{C}^{-1}$ & Specific heat of air at constant pressure \\
\hline$d$ & $\mathrm{~m}$ & Characteristic length scale \\
\hline$D_{0}$ & $\mathrm{~m}$ & Zero-plane displacement \\
\hline$D$ & $\mathrm{kPa}$ & Vapor pressure deficit \\
\hline$E$ & $\mathrm{~mm}$ & Evaporation \\
\hline $\mathrm{EC}$ & & Eddy covariance \\
\hline EF & & Modeling efficiency \\
\hline ET & $\mathrm{mm}$ & Evapotranspiration \\
\hline$g_{\mathrm{a}}$ & $\mathrm{mol} \mathrm{m}^{-2} \mathrm{~s}^{-1}$ & Atmospheric conductance \\
\hline$g_{\mathrm{b}}$ & $\mathrm{mol} \mathrm{m}^{-2} \mathrm{~s}^{-1}$ & Leaf boundary layer conductance \\
\hline$g_{c}$ & $\mathrm{~mol} \mathrm{~m}^{-2} \mathrm{~s}^{-1}$ & Canopy conductance \\
\hline$g_{\mathrm{H}}$ & $\mathrm{mol} \mathrm{m}^{-2} \mathrm{~s}^{-1}$ & Conductance to sensible heat \\
\hline$g_{\mathrm{s}}$ & $\mathrm{mol} \mathrm{m}^{-2} \mathrm{~s}^{-1}$ & Stomatal conductance \\
\hline$g_{\mathrm{v}}$ & $\mathrm{mol} \mathrm{m}^{-2} \mathrm{~s}^{-1}$ & Conductance to water vapor \\
\hline G & $\mathrm{W} \mathrm{m}^{-2}$ & Soil heat flux \\
\hline GS & & April-September growing season \\
\hline Gr & & Grashof number \\
\hline$h$ & $\mathrm{~m}$ & Canopy height \\
\hline$H$ & $\mathrm{~W} \mathrm{~m}^{-2}$ & Sensible heat flux \\
\hline HW & & Hardwood forest ecosystem \\
\hline I & $\mathrm{W} \mathrm{m}^{-2}$ & Radiation closure imbalance \\
\hline$K_{\mathrm{m}}$ & $\mathrm{m}^{2} \mathrm{~s}^{-1}$ & Turbulent diffusion coefficient \\
\hline$l$ & $\mathrm{~m}$ & Mixing length \\
\hline$L$ & $\mathrm{~m}_{\text {leaf }}^{2} \mathrm{~m}_{\text {ground }}^{-2}$ & Leaf area index \\
\hline LE & $\mathrm{W} \mathrm{m}^{-2^{5}}$ & Latent heat flux \\
\hline $\mathrm{OF}$ & & Old field (abandoned agricultural) ecosystem \\
\hline$p_{\mathrm{a}}$ & $\mathrm{kPa}$ & Atmospheric pressure \\
\hline$P$ & $\mathrm{~mm}$ & Precipitation \\
\hline PAD & $\mathrm{m}_{\text {plant }}^{2} \mathrm{~m}_{\text {ground }}^{-2}$ & Plant area density \\
\hline PAI & $\mathrm{m}_{\text {plant }}^{2} \mathrm{~m}_{\text {ground }}^{-2}$ & Plant area index \\
\hline PAR & $\mu \mathrm{mol}$ photons $\mathrm{m}^{-2} \mathrm{~s}^{-1}$ & Photosynthetically active radiation \\
\hline PM & & Penman-Monteith equation \\
\hline $\mathrm{PP}$ & & Planted pine ecosystem \\
\hline $\operatorname{Re}$ & & Reynolds number \\
\hline$R_{\mathrm{i}, \mathrm{s}}$ & $\mathrm{W} \mathrm{m}^{-2}$ & Incident shortwave radiation \\
\hline$R_{\mathrm{n}}$ & $\mathrm{W} \mathrm{m}^{-2}$ & Net radiation \\
\hline$S$ & $\mathrm{C}^{-1}$ & Slope of the saturation mole fraction function \\
\hline SE & & Southeastern United States \\
\hline$T_{\mathrm{a}}$ & $\mathrm{C}$ & Air temperature \\
\hline$T_{\mathrm{c}}$ & $\mathrm{C}$ & Canopy temperature \\
\hline$u$ & $\mathrm{~ms}^{-1}$ & Wind speed \\
\hline$u_{\mathrm{c}}$ & $\mathrm{ms}^{-1}$ & Mean within-canopy wind speed \\
\hline$u_{*}$ & $\mathrm{~ms}^{-1}$ & Friction velocity \\
\hline$\overline{u^{\prime} w^{\prime}}$ & $\mathrm{m}^{2} \mathrm{~s}^{-2}$ & Momentum flux \\
\hline$V_{\text {cmax }}$ & $\mu \mathrm{mol} \mathrm{m}{ }^{-2} \mathrm{~s}^{-1}$ & Maximum carboxylation efficiency \\
\hline$x$ & & Horizontal : vertical leaf projected area \\
\hline$z$ & $\mathrm{~m}$ & Height \\
\hline$z_{\mathrm{H}}$ & $\mathrm{m}$ & Heat roughness length \\
\hline$z_{\mathrm{m}}$ & $\mathrm{m}$ & Momentum roughness length \\
\hline
\end{tabular}


Table 1. (Contd.)

\begin{tabular}{lll}
\hline Abbreviation & Units & Definition \\
\hline$Z_{\mathrm{r}}$ & $\mathrm{m}$ & $\begin{array}{l}\text { Rooting depth } \\
\text { Leaf absorptivity to radiation } \\
\alpha_{\text {leaf }}\end{array}$ \\
$\beta$ & & Bowen ratio \\
$\delta \mathrm{ET}_{\mathrm{GS}}$ & $\mathrm{mm}$ & Change in growing season evapotranspiration \\
$\varepsilon$ & & Emissivity \\
$\lambda$ & $\mathrm{J} \mathrm{mol}^{-1}$ & Latent heat of vaporization \\
$\rho$ & & Soil reflectivity (i.e. albedo) \\
$\sigma$ & $\mathrm{mm} \mathrm{or} \mathrm{W} \mathrm{m}^{-2}$ here & Standard deviation \\
$\sigma_{\mathrm{SB}}$ & $\mathrm{W} \mathrm{m}^{-2} \mathrm{~K}^{-4}$ & Stephen-Boltzmann constant \\
$\theta$ & $\mathrm{m}_{\text {water }}^{3} \mathrm{~m}_{\text {soil }}^{-3}$ & Volumetric soil moisture content \\
$v$ & $\mathrm{~m}^{2} \mathrm{~s}^{-1}$ & Kinematic viscosity \\
$\psi$ & $\mathrm{degrees}_{\Psi}$ & Zenith angle \\
$\Omega$ & & Atmospheric stability \\
$\Omega_{\mathrm{c}}$ & & Decoupling coefficient \\
\hline
\end{tabular}

Table 2 Characteristics of the old field (OF), pine plantation (PP) and hardwood forest (HW) ecosystems and associated eddy covariance (EC) and net radiation $\left(R_{\mathrm{n}}\right)$ measurements

\begin{tabular}{llll}
\hline & OF & PP & HW \\
\hline Mean canopy height $(\mathrm{m})$ & $<1$ & $16(2001)-18(2004)$ & 25 \\
$L\left(\mathrm{~m}^{2} \mathrm{~m}^{-2}\right)$ & $0.1-4$ & $1-5.5$ & $0.1-7$ \\
Basal area $\left(\mathrm{m}^{2} \mathrm{ha}^{-1}\right)$ & 0 & 26.4 & 28.4 \\
EC measurement height $(\mathrm{m})$ & 2.8 & 20.2 & 39.8 \\
$R_{\mathrm{n}}$ measurement height $(\mathrm{m})$ & 4.8 & 22.2 & 41.8 \\
\hline
\end{tabular}

measurements do not resolve the entire spectrum of eddies at both the low- and high-frequency ends (Wilson \& Baldocchi, 2000; Wilson et al., 2002) as discussed in more detail below. We note that $\operatorname{LE}\left(\mathrm{W} \mathrm{m}^{-2}\right)$ is commonly used in energy flux studies and ET $\left(\mathrm{mm} \frac{1}{2}\right.$ $\mathrm{h}^{-1}$ ) is used in the hydrologic studies. These two terms are used interchangeably, depending on context. EC measurements do not independently resolve $T$ or $E$, but estimates are desirable to elucidate physical and biological controls on ET. The model used to partition ET into $T$ and $E$ is discussed in Appendix A.

\section{Latent and sensible heat flux measurements}

LE and $H$ were measured using EC systems comprised of triaxial sonic anemometers (CSAT3, Campbell Scientific, Logan, UT, USA) and in the case of LE, open-path infrared gas analyzers (IRGA, LI-7500, Li-Cor, Lincoln, NE, USA). Measurements of vertical wind velocity, temperature, and scalar concentrations of $\mathrm{H}_{2} \mathrm{O}$ were collected at $10 \mathrm{~Hz}$ and flow statistics were processed in real time using 23X data loggers (Campbell Scientific). The Webb-Pearman-Leuning correction (Webb et al., 1980) for the effects of air density fluctuations on flux measurements was applied to scalar fluxes measured with the open-path LI-7500. A closed-path gas analyzer (LI-6262, Li-Cor) was used at PP before May 1, 2001 and $5 \mathrm{~Hz}$ measurements were postprocessed using procedures described elsewhere (Katul et al., 1997). Topographic variations are minor $(<5 \%)$ and influence flux measurements negligibly (Kaimal \& Finnigan, 1994).

To quantify energy partitioning differences among ecosystems and canopy coupling to the atmosphere, two dimensionless parameters are often used. The Bowen ratio $(\beta)$ is the ratio of $H$ to $L E$ and the decoupling coefficient $(\Omega$, Jarvis \& McNaughton, 1986) is a metric for stomatal control of transpiration:

$$
\Omega=\frac{1+S \lambda c_{p}^{-1}}{1+S \lambda c_{p}^{-1}+g_{\mathrm{va}} g_{\mathrm{vc}}^{-1}}
$$

where $S$ is the slope of the saturation mole fraction and is a function of air temperature $\left(T_{a}\right), c_{p}$ is the specific heat of air and $g_{\mathrm{vc}}$ is surface conductance in the original formulation and modeled $g_{\mathrm{c}}$ here (Appendix B).

\section{Environmental measurements}

Daily $P$ was measured with a rain gauge near the NOAA meteorological station located at OF, and halfhourly $P$ was measured using a tipping bucket (TI, Texas Instruments, Austin, TX, USA) at PP. PAR, $R_{n}$, $T_{a}$, and relative humidity (RH) were sampled every second and averaged for half-hour periods at all three sites. PAR was measured using LI-190SA quantum sensors (Li-Cor). $R_{\mathrm{n}}$ measurements were made with Fritschen-type net radiometers (Q7, REBS, Seattle, WA, USA) through 2003 and with CNR1 net radiometers (Kipp \& Zonen, Delft, the Netherlands) in 2004. The Q7 and CNR1 showed good agreement for 
all ecosystems (data not shown). The CNR1 measures incoming and outgoing solar and far-infrared radiation separately using a coupled pyranometer/pyrgeometer design, enabling surface albedo (i.e. reflectivity, $\rho$ ) measurements. PAR and $R_{\mathrm{n}}$ sensors were $2 \mathrm{~m}$ above EC instrument height at each ecosystem (Table 2). $T_{\mathrm{a}}$ and $\mathrm{RH}$ were measured with HMP35C $T_{\mathrm{a}} / \mathrm{RH}$ probes (Campbell Scientific) positioned at $2 \mathrm{~m}$ at $\mathrm{OF}$ and at two-thirds canopy height at PP and HW. At PP, integrated $0-30 \mathrm{~cm}$ soil moisture $(\theta)$ measurements were made at 12 locations using CS615 $\theta$ sensors (Campbell Scientific), and the mean of these measurements was taken to be site-wide $\theta$. At OF and HW, $\theta$ was measured using Type ML1 ThetaProbe soil moisture sensors (Delta-T Devices, Cambridge, UK). Six sensors were positioned at $10 \mathrm{~cm}$ depth and two sensors at $25 \mathrm{~cm}$ depth near the respective tower. Average $\theta$ was computed for the 10 and $25 \mathrm{~cm}$ depths and the mean of the two depths was taken to obtain a single value for $\theta$ that is comparable with PP.

\section{Leaf area index measurements}

In 2001, $L$ at $\mathrm{OF}$ was estimated by measuring PAR transmission with a series of 80 quantum sensors (AccuPAR model PAR-80 Ceptometer, Decagon Instruments, Pullman, WA, USA) to calculate gap fractions, which were inverted to calculate $L$ after Norman \& Campbell (1989; see Novick et al. 2004). After 2001, L at OF was estimated using a combination of litter data and LAI-2000 plant-canopy analyzer (Li-Cor) measurements. At PP, the contribution to $L$ from $P$. taeda trees was calculated using needle elongation and litterfall measurements, and $L$ of understory hardwood species was calculated using degree-day sums and litterfall measurements (McCarthy et al., 2006). At HW, L was determined using LAI-2000 measurements adjusted to match litterfall data (Palmroth et al., 2005). Plant area density (PAD) was determined using profile LAI-2000 measurements at all ecosystems.

\section{Data filtering}

Care must be taken to ensure that EC measurements represent a turbulent flux from the land surface, and in our case must be rigorously filtered to ensure that the flux footprint lies within ecosystem dimensions (Fig. 1). Flux data were filtered using four criteria. (1) Data were removed if they exceeded logical maxima and minima, determined to be 800 and $-100 \mathrm{~W} \mathrm{~m}^{-2}$, respectively, for LE and $H$ (i.e. 'Logical' filter, Table 3 below). (2) The effects of excessive sensor noise were filtered by removing points for which scalar variance exceeded $4 \mathrm{~g} \mathrm{H}_{2} \mathrm{O} \mathrm{m}^{-3}$ and $4{ }^{\circ} \mathrm{C}$ for the IRGA and sonic anem-
Table 3 The percentage of flux data remaining after progressively employing four data filters

\begin{tabular}{llll}
\hline Ecosystem & Filter & Daytime & Total \\
\hline OF & Logical & 85 & 83 \\
& Instrument & 83 & 81 \\
& Wind Directional & 79 & 77 \\
PP & Atmospheric Stability & 79 & 41 \\
& Logical & 83 & 83 \\
& Instrument & 77 & 76 \\
HW & Wind Directional & 74 & 73 \\
& Atmospheric Stability & 65 & 35 \\
& Logical & 93 & 92 \\
& Instrument & 89 & 89 \\
& Wind Directional & 76 & 75 \\
& Atmospheric Stability & 61 & 32 \\
\hline
\end{tabular}

The 'logical' filter removes unrealistic data points. The instrument filter ensures proper sonic anemometer and IRGA function. The wind directional filter removes fluxes potentially contaminated by advection. The atmospheric stability filter ensures both that measurements are taken under conditions of sufficient turbulence and that the bulk of the flux footprint Hsieh et al. (2000); Detto et al. (2006) arises from the ecosystem of interest.

OF, old field; PP, planted pine forest; HW, hardwood forest.

ometer, respectively. (3) Flux data were removed if the inverse tangent of the ratio between $\bar{u}$ and $\frac{1}{2}$ hourly mean vertical wind velocity $(\bar{w})$ was greater than $15^{\circ}$ to ensure that the mean streamlines remain almost parallel to the ground (i.e. $<5 \%$ of measured flux as in Detto et al., 2006), and HW flux data were removed if mean wind direction was less than $40^{\circ}$ or exceeded $350^{\circ}$ when distortion from the tower and a nearby canopy gap was largest. (4) To ensure that data represent a turbulent flux that originates from the ecosystem of interest in a probabilistic sense, we used the rigorous atmospheric stability ( $\Psi$ ) filter of Novick et al. (2004), which requires that night-time data (defined here as periods for which solar zenith angle $>90^{\circ}$ ) are measured under nearneutral $\Psi$, and that the peak of the source-weight function (using the footprint model of Hsieh et al., 2000) does not exceed ecosystem dimensions. In this way measured fluxes for which the peak of the source weight function originates outside the ecosystem of interest (e.g. from the clear-cut at HW) were excluded from this analysis. The percentages of EC data remaining after progressively applying each filter are listed in Table 3.

\section{Gapfilling}

EC time series incorporate many missing data 'gaps', but continuous time series are preferred for ET estima- 
tion on seasonal or annual time scales (Falge et al., 2001). When the measurement of any meteorological variable was unavailable due to equipment failure or other error, a continuous record was obtained by fitting a linear regression between measurements from the sensor of interest and a nearby sensor of the same type using a windowing function that modeled temporally local data appropriate for the size of the gap [i.e. at least $25 \%$ of the size of the gap, with a coefficient of determination $\left(r^{2}\right)$ of at least 0.9]. Missing $H$ data were also gapfilled in this way using linear temporally local relationships with $R_{\mathrm{n}}$.

When sonic anemometer measurements of $\bar{u}$ were not available, we approximated $u$ using cup anemometer measurements made at PP and maintained by Brookhaven National Laboratories. We note that cup anemometer measured mean wind speed is 'contaminated' by the turbulent kinetic energy, but cup and sonic anemometer mean velocity measurements were strongly related $\left(r^{2}=0.75\right)$.

Missing LE data was gapfilled using the Penman Monteith (PM) equation and tested against a simpler $g_{c}$ model (Jarvis, 1976; Oren et al., 1999) as described in Appendix B. Canopy wind speed $\left(u_{\mathrm{c}}\right)$ is required to model conductances to water vapor and sensible heat ( $g_{\mathrm{v}}$ and $g_{\mathrm{H}}$, respectively) for the PM equation and was modeled by a first-order canopy turbulence model also described in Appendix B. Canopy conductance parameters for both models were fit for monthly periods via least squares regression using the Gauss-Newton algorithm standard in MATLAB (Mathworks Inc., Boston, MA, USA).

\section{Error estimation}

Error in annual ET estimates was calculated following a standard approach (Goulden et al., 1996; Moncrieff et al., 1996) that combines error due to gapfilling - also called 'sampling uncertainty' (SU) - in flux estimates with the 'uniform systematic error' (USE) of each EC system. SU was determined by simulating the impact of the standard error of the fitted monthly canopy conductance parameters in the PM equation (Appendix B) on annual ET estimates using Monte Carlo simulations with 100 realizations. The variance from the resulting distribution of annual flux estimates represents an estimate of the error due to SU.

In the original formulation, USE was estimated for each EC system for each year by sampling night-time LE, which should approximate $0 . R_{\mathrm{n}}$ is negative at night, thus night-time LE measurements may deviate from 0 (e.g. due to condensation). Also, for high $u_{*}$, the Eddydiffusivity near the canopy top is large; hence, any small gradients in mean water vapor concentration may lead to a finite flux not associated with water vapor production from foliage or forest floor, but rather stored water vapor concentration leaving the canopy air space. Finite LE may also occur when nocturnal radiative perturbations associated with the passage of clouds induce instabilities and local production of turbulence within the canopy (Cava et al., 2004). Again, this flux is better approximated as a storage flux rather than a biosphere-atmosphere flux. Thus, we excluded conditions for which $u_{*}>0.2 \mathrm{~m} \mathrm{~s}^{-1}$, the absolute value of $\Psi$ is $<0.1$, or if the standard deviation of $R_{\mathrm{n}}$ is greater than $5 \mathrm{~W} \mathrm{~m}^{-2}$, a surrogate for potential passage of clouds. Deviance from 0 flux in the remaining data is assumed to be 'inherent' error in the flux measurements. These inherent errors followed a Laplacian distribution (Hollinger \& Richardson, 2005; Richardson et al., 2006), the standard deviation of which is $\sigma=\sqrt{2} b$ and the unbiased estimator for the scale parameter $b$ is $\sum_{i=1}^{N}\left|x_{\mathrm{i}}-\bar{x}\right| / N$ where $N$ is the length of the data series and $\bar{x}$ is the mean night-time LE measurement. This standard deviation of night-time fluxes was divided by average daytime LE and multiplied by the annual or seasonal flux estimate to calculate USE (Goulden et al., 1996). Total error was calculated by combining variances due to SU and USE, and is reported as a $\pm 1 \sigma$ interval about estimated annual ET.

\section{Results}

We begin by briefly discussing climatic variability across the measurement period and analyzing the $R_{\mathrm{n}}$ balance closure at each site to assess how much of the differences in observed ET are due to vegetation. We then discuss the partitioning of $R_{\mathrm{n}}$, focusing on annual and $\mathrm{ET}_{\mathrm{GS}}$ and its relationship to external and internal drivers and its components, $T$ and $E$, with an analysis of techniques for gapfilling and error estimation.

\section{Climatic variability}

GS (April-September) precipitation $\left(P_{\mathrm{GS}}\right)$ was $529 \mathrm{~mm}$ in 2001 (hereafter 'mild drought'), $371 \mathrm{~mm}$ in 2002 ('severe drought'), $790 \mathrm{~mm}$ in 2003 ('wet'), and $661 \mathrm{~mm}$ in 2004 ('average'), about $1 \sigma$ below, $2 \sigma$ below, $1 \sigma$ above and near the long-term (111 year) mean $P_{\mathrm{GS}}$ of $632 \pm 130 \mathrm{~mm}$, respectively (Fig. 2a). The sum of $\mathrm{PAR}_{\mathrm{GS}}$ was nearly equal in 2001 and 2002, but ca. 10\% less than 2001-2002 levels in 2003 and 2004, due to the cloudier conditions (Fig. 2b). Mean $T_{\mathrm{a}}$, GS differed by more than $1.5^{\circ} \mathrm{C}$ among years; 2001 and 2003 were relatively cooler and 2002 and 2004 were relatively warmer (Fig. 2c). $P$ (Fig. 2a), PAR (Fig. 2b), and $T_{a}$ at $2 / 3$ canopy height in the forested ecosystems and at $2 \mathrm{~m}$ at OF (Fig. 2c) did not differ appreciably among the adjacent ecosystems, 


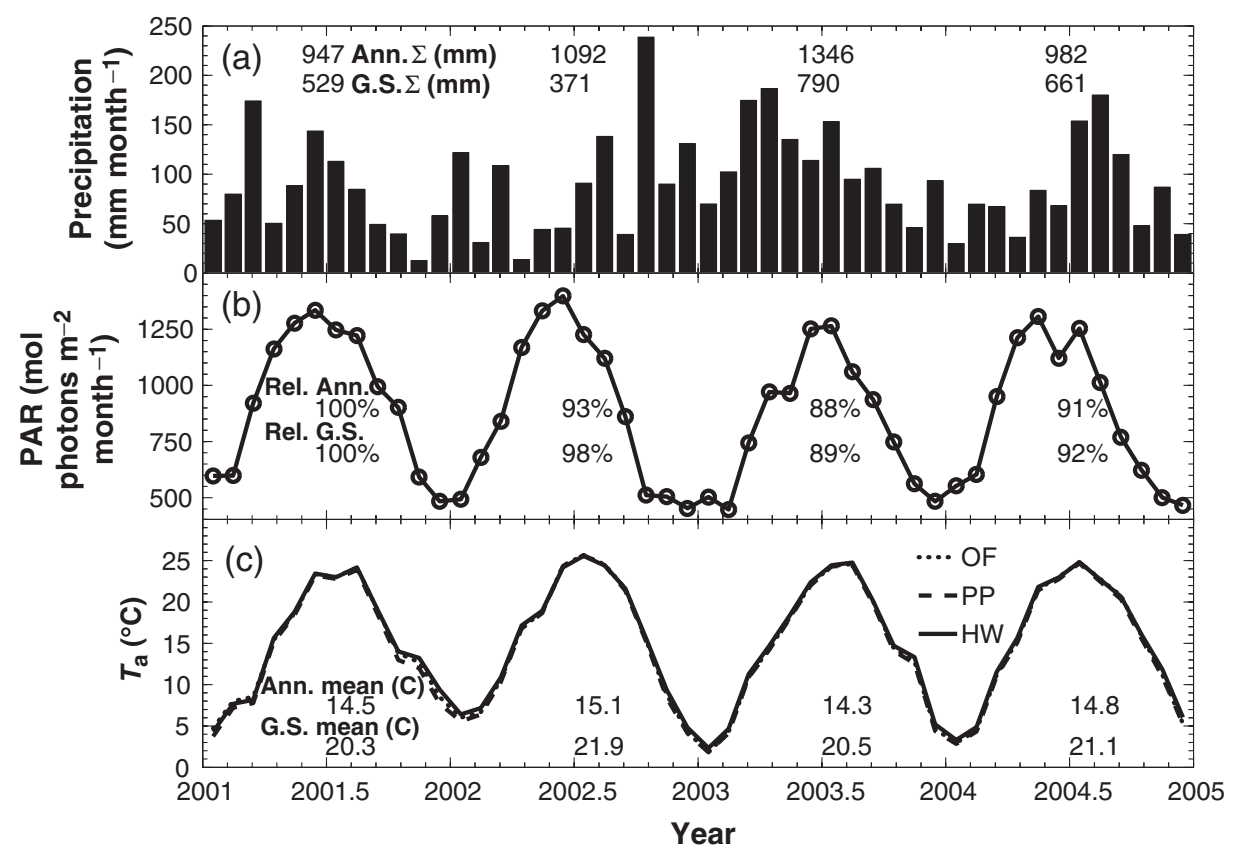

Fig. 2 Precipitation $(P, a)$, photosyntheically active radiation (PAR, b) and air temperature $\left(T_{a}, c\right)$ did not differ appreciably among the adjacent ecosystems.

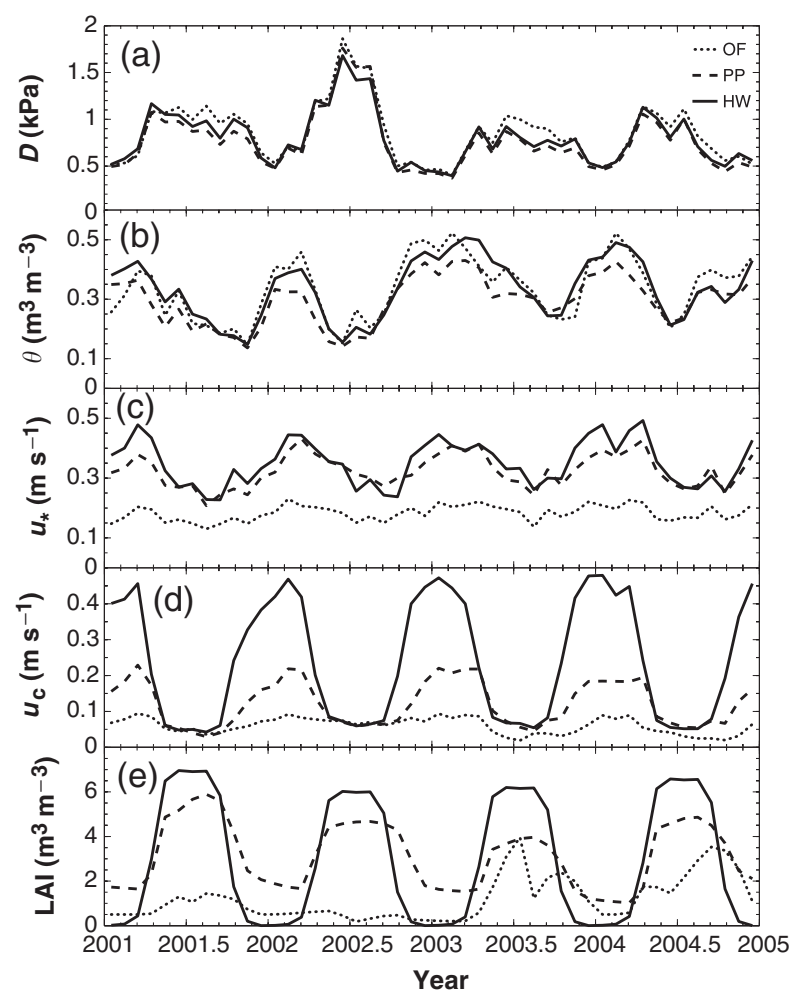

Fig. 3 Vapor pressure deficit $(D, a)$, soil moisture $(\theta, b)$, friction velocity $\left(u_{*}, \mathrm{c}\right)$, modeled canopy wind speed $\left(u_{\mathrm{c}}, \mathrm{d}\right)$ and leaf area index $(L, \mathrm{e})$, differed among ecosystems. with the latter influenced slightly by the state of the canopy. Parts of OF are shaded at sunup and sundown due to nearby forest edges. These conditions occur during low PAR periods and are considered negligible for long-term ET estimates.

Any differences among ecosystems in micrometeorological and edaphic variables such as $D$ (Fig. 3a) and $\theta$ (Fig. 3b) can be attributed to the influence of vegetation to a first order (Palmroth et al., 2005). For example, $\theta$ was higher at HW than OF and PP during winter when leaf area is absent and transpiration ceases (Fig. 3b). As expected, the rougher canopy (HW) also experienced the highest momentum sink $\left(=-u_{*}^{2}\right)$ during maximum foliage (Fig. 3c), and in the winter, the $u_{*}$ for PP and HW were comparable despite significant differences in wintertime $L$ (Fig. 3e). At $\mathrm{OF}, u_{*}$ did not exhibit marked seasonal trends despite strong $L$ variability.

\section{Radiation balance closure}

LE and $H$ dominated the radiation balance and comprised $66 \%, 75 \%$, and $66 \%$ of $R_{\mathrm{n}}$ at OF, PP, and HW, respectively, on the $\frac{1}{2}$ hourly basis. The greater contribution of LE and $H$ at PP is logical given its higher relative leaf area in winter and lower $G$. We measured $G$ and below canopy $R_{\mathrm{n}}$ intermittently and found this term to be small relative to LE and $H$, but it could exceed $100 \mathrm{~W} \mathrm{~m}^{-2}$ when LAI was low at OF and HW, and when direct solar radiation penetrated a gap at PP 
and HW. To minimize the effects of $G$ on the energy balance closure, we computed radiation balance closure at the daily time step, which was $72 \%$ at OF, $77 \%$ at PP, and $65 \%$ at HW. This lack of closure is greater than reported in the synthesis of Wilson et al. (2002) who found a mean radiation balance closure of $80 \%$ across a wide range of FLUXNET sites. We attribute the observed $I$ to low-frequency losses and entrainment during convective conditions rather than other common explanations for $I$ (e.g. Wilson et al., 2002) as discussed in Appendix C; these events are likely to impact $H$ more than LE. Appendix C (see Fig. 10) suggests that the lack of energy closure strongly varies with atmospheric stability - with near-convective conditions experiencing the largest $I$.

\section{Models for gapfilling missing data}

Compared with the Jarvis-type model, the PM model for bimonthly periods with full accounting of atmospheric, leaf boundary layer and stomatal conductances (Appendix B) resulted in the best fit with measured LE for all ecosystems (Table 4). The slope between model and measurements was closest to unity, the intercept was closest to 0 , and the parameter estimates consistently converged. Hence, it was the logical choice for gapfilling missing ET data.

Interestingly, model-fitting statistics were not compromised by dramatically simplifying the gapfilling model. Replacing PM with the Jarvis type $g_{c}$ model [i.e. Eqns (B2) and (B3) alone], with proper unit correction, resulted in comparable root mean-squared error (RMSE) and modeling efficiency (EF, Loague \& Green, 1991; Meyer \& Butler, 1993) despite the fact that it is a model for $T$, not ET (Table 4). In this way, accurate simplifications to ET models may be achieved with

Table 4 Model-fitting statistics for ET for the full PenmanMonteith model (PM, Eqn 2), and a Jarvis-type model after Oren et al. (1999) (Eqn B3)

\begin{tabular}{llllll}
\hline \multirow{2}{*}{ Ecosystem } & Model & Slope & $\begin{array}{l}\text { Intercept } \\
\left(\mathrm{W} \mathrm{m}^{-2}\right)\end{array}$ & $\begin{array}{l}\text { RMSE } \\
\left(\mathrm{W} \mathrm{m}^{-2}\right)\end{array}$ & EF \\
\hline OF & PM & 0.87 & 16 & 62 & 0.56 \\
& Jarvis & 0.70 & 26 & 59 & 0.60 \\
PP & PM & 0.82 & 22 & 45 & 0.81 \\
& Jarvis & 0.82 & 20 & 46 & 0.80 \\
HW & PM & 0.77 & 27 & 62 & 0.73 \\
& Jarvis & 0.75 & 29 & 61 & 0.73 \\
\hline
\end{tabular}

RMSE is the root mean square error and EF is modeling efficiency.

OF, old field; PP, planted pine forest; HW, hardwood forest. knowledge of only PAR, $D, L$, and, during drought periods, of $\theta$ (or as a surrogate, $P$ ) as well. This finding already suggests that much of the variability in ET is driven by $T$.

\section{Radiation balance partitioning}

$R_{\mathrm{n}}$ (Fig. 4a) followed the seasonal pattern at all ecosystems. $H$ (Fig. $4 \mathrm{~b}$ ) values were comparable at $\mathrm{OF}$ and PP during all periods except after the ice storm. LE was lower at $\mathrm{OF}$ than the forested ecosystems during most GS periods, and LE at PP was generally larger than or comparable to HW with the exception of the 2002 severe drought-GS (Fig. 4c). HW had the largest wintertime $R_{\mathrm{n}}$; low LE was compensated by larger $H$ fluxes.

Low $\mathrm{LE}$ and high $H$ during severe drought at $\mathrm{OF}$ and PP resulted in a dramatic increase in mean daytime $\beta$ (Fig. 5a); the summertime $\beta$ at HW was consistently low due to high LE and low $H$ fluxes regardless of drought conditions, and the wintertime $\beta$ was consistently highest due to very low LE. The $\Omega$ showed the expected response under all conditions except severe drought (Fig. 5b). High $\Omega$ values at OF were indicative of $R_{\mathrm{n}}$ limitation, and the $\Omega$ was lowest on average at the needle-leafed PP because $g_{\mathrm{c}}$ was well-coupled to atmospheric demand. Interestingly, the $\Omega$ at OF approached values typical of PP during the peak of the drought in 2002 , indicating that $g_{c}$ at these two different canopies was similarly limited.

\section{Water vapor fluxes at the annual time scale}

Interecosystem differences in $R_{\mathrm{n}}$ balance partitioning (Fig. 4a-c) resulted in annual and GS sums of ET, T, and $E$ that varied among ecosystems and across years and

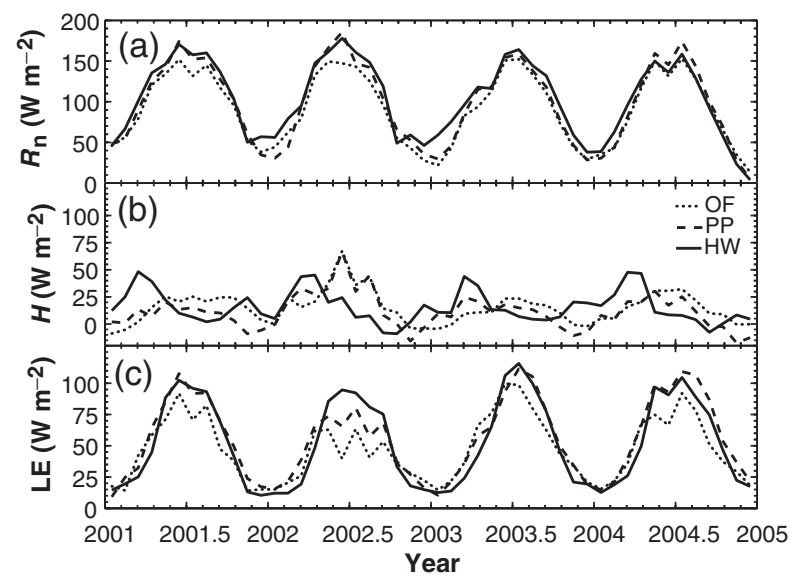

Fig. 4 Monthly average net radiation $\left(R_{\mathrm{n}} \mathrm{a}\right)$, latent heat (LE, b), and sensible heat $(H, \mathrm{c})$ fluxes for the three study ecosystems. 
GSs (Fig. 6a, Table 5). Annual ET was characteristically lower at $\mathrm{OF}$ than the forested ecosystems except during the wet 2003, when it was similar to ET at HW. Annual ET at PP was in general greater than at HW, but usually within the range of estimated error. ET at HW slightly exceeded PP during the severe drought (2002) and exhibited relatively low interannual variability.

Total error in annual ET varied between $7 \%$ and $14 \%$, consistent with other studies (Meyers, 2001; Wilson \& Meyers, 2001). Total error was dominated by the USE (i.e. systematic error) component rather than the $\mathrm{SU}$ (gapfilling) component (Table 5), suggesting that error due to gapfilling is small and that models used for

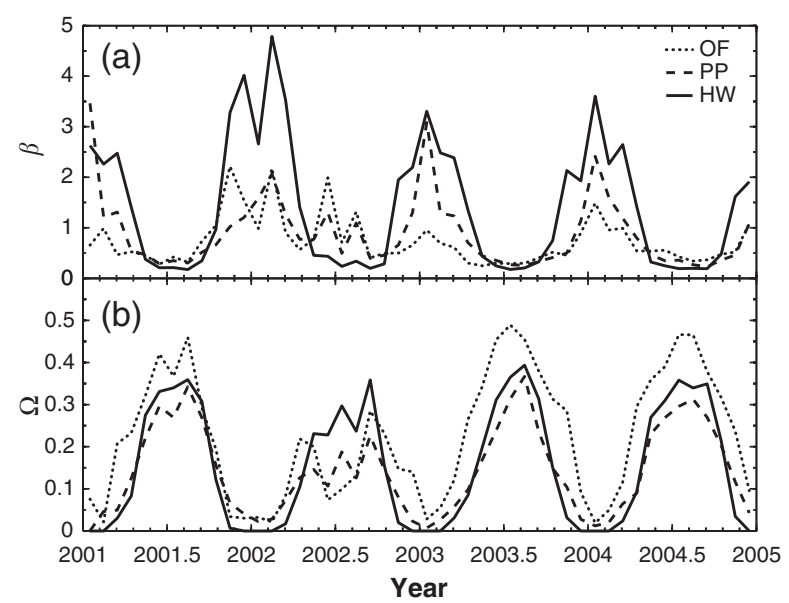

Fig. 5 Mean Bowen ratio $(\beta$, a), simplified here as the monthly average of daytime $H / L E$, and the decoupling coefficient $(\Omega, \mathrm{b})$. gapfilling are sufficiently accurate for estimating seasonal or annual ET sums, and also that efforts to reduce error in EC systems should focus on systematic error.

Modeled T (Table 5, Fig. 6b) decreased from 290 to $160 \mathrm{~mm}$ at $\mathrm{OF}$ as the drought progressed, then increased dramatically to $430 \mathrm{~mm}$ during the wet year and decreased by $70 \mathrm{~mm}$ between the wet and normal years.

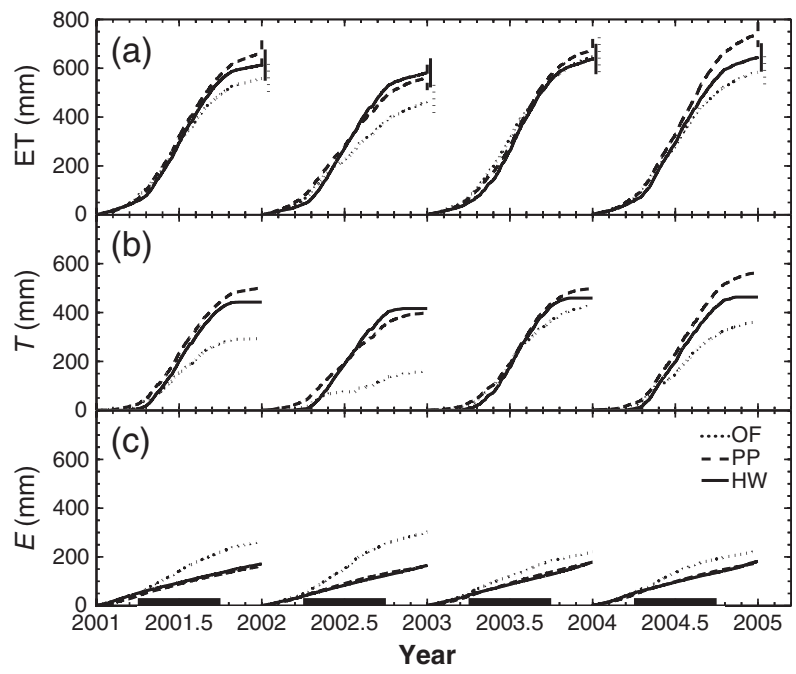

Fig. 6 Cumulative evapotranspiration (ET) for old field (OF), pine plantation (PP) and oak-hickory hardwood forest (HW) ecosystems for 2001-2004 with flux error $( \pm 1 \sigma)$ estimated after (Goulden et al., 1996). Growing seasons are indicated by horizontal bars. (b) Same as (a) but for cumulative transpiration (T) estimates. (c) Same as (a) but for cumulative evaporation $(E)$ estimates.

Table 5 Annual and growing season (GS) evapotranspiration (ET), transpiration ( $T$ ), and evaporation (E) estimates with associated error about annual ET estimates as estimated after Goulden et al. (1996)

\begin{tabular}{|c|c|c|c|c|c|c|c|c|c|c|}
\hline Ecosystem & Year & ET & $T$ & $E$ & $\mathrm{ET}_{\mathrm{GS}}$ & $T_{\mathrm{GS}}$ & $E_{\mathrm{GS}}$ & USE & $\mathrm{SU}$ & Total Error \\
\hline \multirow[t]{4}{*}{ OF } & 2001 & 560 & 290 & 260 & 420 & 250 & 170 & 59 & 4 & 59 \\
\hline & 2002 & 460 & 160 & 300 & 320 & 120 & 200 & 68 & 3 & 68 \\
\hline & 2003 & 650 & 430 & 220 & 480 & 350 & 130 & 79 & 2 & 79 \\
\hline & 2004 & 580 & 360 & 220 & 430 & 290 & 140 & 65 & 2 & 65 \\
\hline \multirow[t]{4}{*}{ PP } & 2001 & 660 & 500 & 160 & 510 & 420 & 90 & 53 & 7 & 53 \\
\hline & 2002 & 560 & 400 & 160 & 410 & 320 & 90 & 51 & 10 & 52 \\
\hline & 2003 & 670 & 500 & 180 & 510 & 410 & 100 & 44 & 7 & 45 \\
\hline & 2004 & 740 & 560 & 180 & 550 & 460 & 100 & 51 & 3 & 51 \\
\hline \multirow[t]{4}{*}{ HW } & 2001 & 610 & 440 & 170 & 490 & 410 & 80 & 63 & 10 & 64 \\
\hline & 2002 & 580 & 410 & 160 & 480 & 390 & 90 & 59 & 9 & 60 \\
\hline & 2003 & 640 & 460 & 180 & 510 & 420 & 90 & 62 & 7 & 62 \\
\hline & 2004 & 640 & 460 & 180 & 500 & 420 & 80 & 58 & 4 & 58 \\
\hline
\end{tabular}

USE is 'uniform systematic error' and SU is 'sampling uncertainty'. All units are in mm. Component fluxes may not equal ET due to rounding.

OF, old field; PP, planted pine forest; HW, hardwood forest. 
At PP, $T$ decreased by $100 \mathrm{~mm}$ between mild and severe droughts, then returned to 2001 levels during the wet year (2003) after the ice storm. $T$ increased to $560 \mathrm{~mm}$ in 2004 despite less $P$. $T$ was nearly invariant at HW and changed by a maximum of ca. $50 \mathrm{~mm}$ between severe drought and wet conditions.

Modeled $E$ (Fig. 6c) was larger at OF than the other ecosystems, increased by $40 \mathrm{~mm}$ from mild to severe drought, and was similar $(220 \mathrm{~mm})$ in 2003 and 2004 with different seasonal patterns. $E$ at PP was similar for all years and increased by only $20 \mathrm{~mm}$ during the wet year when $L$ was lower due to ice-storm impacts. Likewise, $E$ at HW was consistent between years and increased by only $20 \mathrm{~mm}$ between severe drought and wet years.

\section{Relationships between $E T_{G S}$ and environmental drivers}

$\mathrm{ET}_{\mathrm{GS}}$ at $\mathrm{OF}$ and $\mathrm{PP}$ was sensitive to $P$, less so at HW (Table 5, Fig. 7a). The large reduction in $L_{\mathrm{GS}}$ at $\mathrm{PP}$ after the December 2002 ice storm (McCarthy et al., 2006) caused the relationship between $\mathrm{ET}_{\mathrm{GS}}$ and $P_{\mathrm{GS}}$ to fall below the linear response observed during other years (Fig. 7a). This effect was not observed in the other ecosystems. Consequently, average $P_{\mathrm{GS}}$ in 2004 decreased $\mathrm{ET}_{\mathrm{GS}}$ from 2003 levels by over 10\% at OF, but increased $\mathrm{ET}_{\mathrm{GS}}$ by nearly $8 \%$ at $\mathrm{PP}$ as the canopy recovered from ice-storm damage (Table 5, Fig. 7a). In contrast, $\mathrm{ET}_{\mathrm{GS}}$ at $\mathrm{HW}$ changed by $6 \%$ or less between consecutive years (Table 5). The resulting relationship between $P_{\mathrm{GS}}$ and $\mathrm{ET}_{\mathrm{GS}}$ was nearly linear for all ecosystems, especially HW (Fig. 7a).

$\mathrm{ET}_{\mathrm{GS}}$ decreased with increasing GS mean $D\left(D_{\mathrm{GS}}\right)$ at all ecosystems (Fig. 7b), suggesting that plant controls on transpiration, not increased $E$, dominated the ET signal under high $D$ at the GS time scale. It is interesting to note that $\mathrm{OF}$ increased growing season $L\left(L_{\mathrm{GS}}\right)$ and thus ET in response to optimal growth conditions during 2003 and 2004 (Fig. 7c), but the forested ecosystems increased mean growing season $g_{\mathrm{s}}\left(g_{\mathrm{s}, \mathrm{GS}}\right)$, as estimated from Eqn (B3), rather than $L$ (Fig. 7d). Thus, $\mathrm{ET}_{\mathrm{GS}}$ was primarily driven by changes in $P, D, L$, and $g_{\mathrm{s}}$. The response of $\mathrm{ET}_{\mathrm{GS}}$ to the product of these variables is approximately linear across all ecosystems (Fig. 8):

$$
\mathrm{ET}_{\mathrm{GS}} \approx a P_{\mathrm{GS}} D_{\mathrm{GS}} L_{\mathrm{GS}} g_{\mathrm{s}, \mathrm{GS}}+b .
$$

We use this simple model to isolate the relative contribution of the physical $(P, D)$ and biological factors $\left(L, g_{\mathrm{s}}\right)$ that give rise to changes in $\mathrm{ET}_{\mathrm{GS}}$ through a linear perturbation analysis similar to Wilson and Baldocchi (2000). Briefly, if we consider changes in $\mathrm{ET}_{\mathrm{GS}}\left(\delta \mathrm{ET}_{\mathrm{GS}}\right)$, the total derivative of Eqn (3) is represented by a
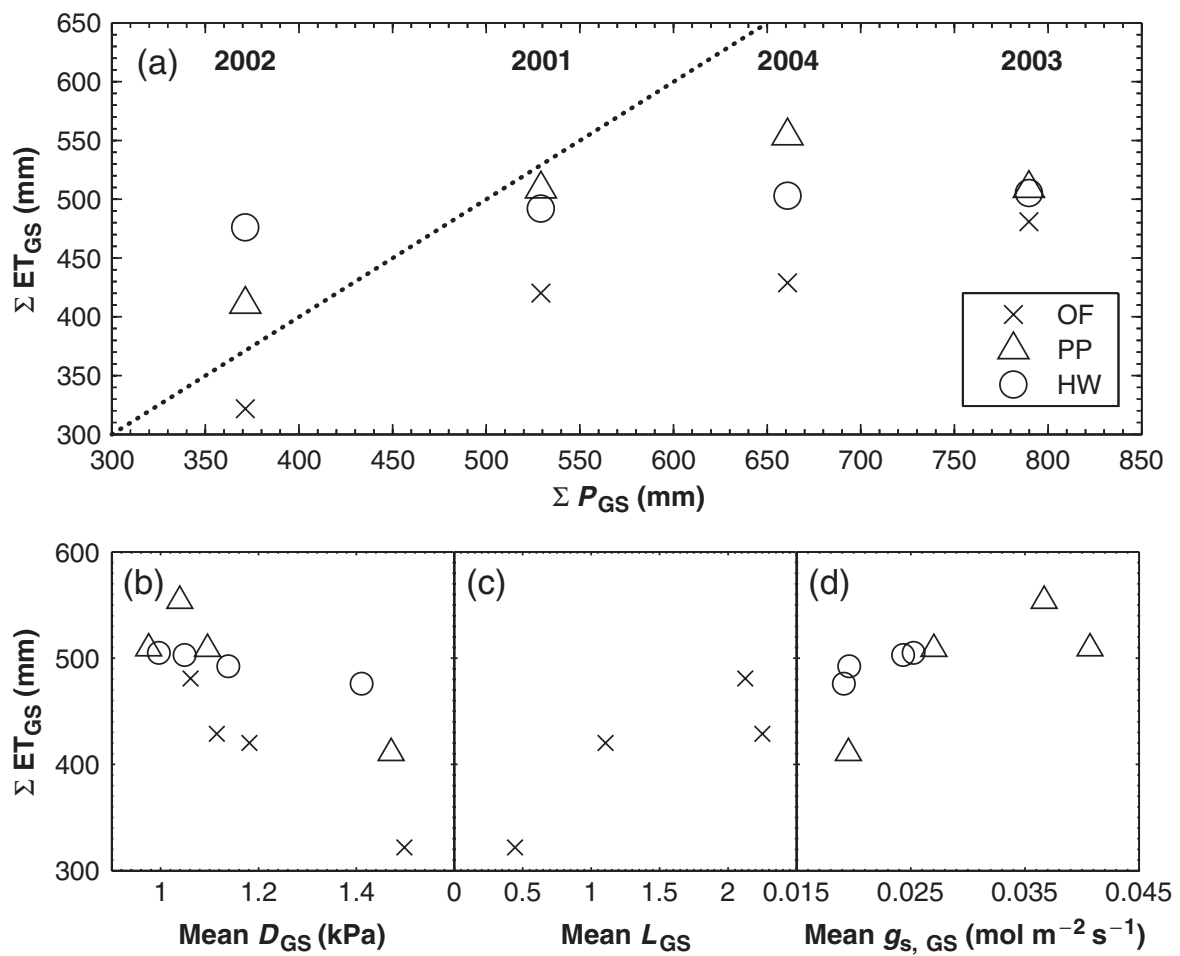

Fig. 7 The sum of April-September growing season evapotranspiration (ET) vs. precipitation $(P, a)$, mean vapor pressure deficit $(D, b)$, mean leaf area index $(L, \mathrm{c})$, and stomatal conductance $\left(g_{\mathrm{s}}, \mathrm{d}\right)$. 


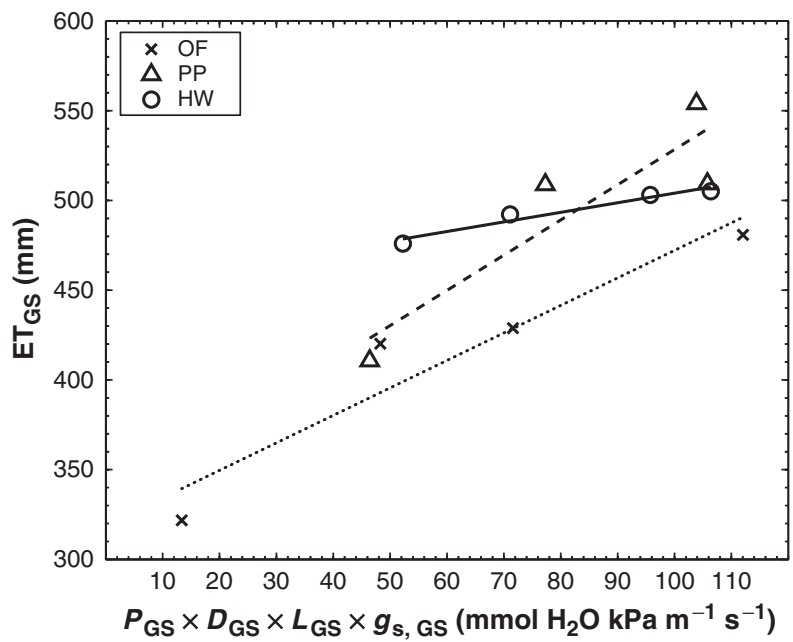

Fig. 8 The differential sensitivity of growing season evaportanspiration $\left(\mathrm{ET}_{\mathrm{GS}}\right)$ of the study ecosystems to the combination of precipitation $(P)$, vapor pressure deficit $(D)$, and leaf area index $(L)$ and stomatal conductance $\left(g_{\mathrm{s}}\right)$.

multivariate Taylor's expansion:

$$
\begin{aligned}
\delta \mathrm{ET}_{\mathrm{GS}} & \approx\left(\frac{\partial \mathrm{ET}_{\mathrm{GS}}}{\partial P_{\mathrm{GS}}} \mathrm{d} P_{\mathrm{GS}}+\frac{\partial \mathrm{ET}_{\mathrm{GS}}}{\partial D_{\mathrm{GS}}} \mathrm{d} D_{\mathrm{GS}}\right. \\
& \left.+\frac{\partial \mathrm{ET}_{\mathrm{GS}}}{\partial L_{\mathrm{GS}}} \mathrm{d} L_{\mathrm{GS}}+\frac{\partial \mathrm{ET}_{\mathrm{GS}}}{\partial g_{\mathrm{s}, \mathrm{GS}}} \mathrm{d} g_{\mathrm{s}, \mathrm{GS}}\right) \\
& +\frac{1}{2 !} \frac{\partial^{2} \mathrm{ET}_{\mathrm{GS}}}{\partial^{2} P_{\mathrm{GS}}}\left(\mathrm{d} P_{\mathrm{GS}}\right)^{2}+\cdots,
\end{aligned}
$$

where the higher-order terms are neglected in this firstorder analysis. Using Eqn (3),

$$
\begin{aligned}
& \frac{\partial \mathrm{ET}_{\mathrm{GS}}}{\partial P_{\mathrm{GS}}}=a D_{\mathrm{GS}} L_{\mathrm{GS}} g_{\mathrm{s}, \mathrm{GS}}, \\
& \frac{\partial \mathrm{ET}_{\mathrm{GS}}}{\partial D_{\mathrm{GS}}}=a P_{\mathrm{GS}} L_{\mathrm{GS}} g_{\mathrm{s}, \mathrm{GS}}, \\
& \frac{\partial \mathrm{ET}_{\mathrm{GS}}}{\partial L_{\mathrm{GS}}}=a P_{\mathrm{GS}} D_{\mathrm{GS}} g_{\mathrm{s}, \mathrm{GS}}, \\
& \frac{\partial \mathrm{ET}_{\mathrm{GS}}}{\partial g_{\mathrm{s}, \mathrm{GS}}}=a P_{\mathrm{GS}} D_{\mathrm{GS}} L_{\mathrm{GS}} .
\end{aligned}
$$

It is important to note that $g_{\mathrm{s}}$ is expected to change with time owing to both external and internal factors. For example, the Fick's law relationship for net photosynthesis $A_{\mathrm{n}}$ coupled with $T$, which is a function of $g_{\mathrm{s}}$ [Eqn (B2)], can be expressed as $T=\left(1.6 A_{\mathrm{n}} D\right) /\left(C_{\mathrm{a}}-C_{\mathrm{i}}\right)$ (Katul et al., 2003) where $C_{\mathrm{a}}$ is atmospheric $\mathrm{CO}_{2}$, and $C_{\mathrm{i}}$ is leaf-internal $\mathrm{CO}_{2}$. Thus, $g_{s}$ is expected to change with variables that influence leaf $A_{\mathrm{n}}$ including, for example, maximum carboxylation efficiency $V_{\text {cmax }}$, which is variable in time in these ecosystems due to temperature acclimation and leaf nitrogen variations (Ellsworth, 2000; Wilson et al., 2001; Juang et al., 2006).

The model matches measurements well despite the linearity assumption (Figs 8 and 9). $\mathrm{ET}_{\mathrm{GS}}$ at $\mathrm{OF}$ and $\mathrm{PP}$ were the most sensitive to the combination of external and internal drivers (i.e. they had the highest slope in Fig. 8), and HW was least sensitive. Internal (i.e. biological) adjustment dominated $\delta \mathrm{ET}_{\mathrm{GS}}$ at $\mathrm{OF}$ over the measurement period (Fig. 9a) and dominated $\delta \mathrm{ET}_{\mathrm{GS}}$ at PP during the drought years (Fig. 9b). The impact of biological and climatic drivers opposed each other at PP during the wet year after the ice storm. $\delta \mathrm{ET}_{\mathrm{GS}}$ at $\mathrm{HW}$ was small, and the contribution of physical and biological factors were approximately equal (Fig. 9c). To ensure that these findings are not overly sensitive to the choice of the model, we repeated the entire analysis using the full PM model [Eqn (B1)] in Appendix D. From Appendix D, we found that the relative role of internal vs. external drivers is the same as Fig. 9. Individual aspects of the linear perturbation analysis (Fig. 9d-f) are discussed in more detail below.

\section{Discussion}

We begin by noting some aspects of the environmental measurements that are of particular importance to water cycling, namely $\theta$, canopy wind speed and momentum flux, and $R_{\mathrm{n}}$. Next, we discuss the outcome of the linear perturbation analysis within the context of this experiment and contrast our findings with other studies, focusing on longer-term dynamics. The broader implications of these findings on water resources in the SE are also discussed.

\section{Site characteristics}

Interestingly, $\mathrm{ET}_{\mathrm{GS}}$ exceeded $P_{\mathrm{GS}}$ in 2002 by 30 and $100 \mathrm{~mm}$ at PP and HW, respectively, suggesting that the GS root-zone storage must have been depleted by these amounts. If we consider the soil water balance $n Z_{\mathrm{r}}(\mathrm{d} \theta / \mathrm{d} t)$ (Porporato et al., 2002) where $n$ is porosity $\left(0.54 \mathrm{~m}^{3} \mathrm{~m}^{-3}\right.$, Oren et al. (1998) and $\mathrm{d} \theta / \mathrm{d} t$ is the change in soil moisture during the $2002 \mathrm{GS}\left(0.19 \mathrm{~m}^{3} \mathrm{~m}^{-3}\right.$ at PP and $0.27 \mathrm{~m}^{3} \mathrm{~m}^{-3}$ at HW, Fig. $\left.3 \mathrm{~b}\right)$, then rooting depth $\left(Z_{\mathrm{r}}\right)$ is estimated to be shallow, ca. $30-50 \mathrm{~cm}$ at both ecosystems. A clay pan was observed at $35 \mathrm{~cm}$, which is also the depth at which water uptake balanced transpiration at PP (Oren et al., 1998). Trenching experiments and tipups in the forested ecosystems further suggest that this approximation is robust. At OF, roots did not develop below $45 \mathrm{~cm}$ (Lai \& Katul, 2000), and observed ET was well described using a root water capture model that was active to $35 \mathrm{~cm}$ depth. Coupled with existing studies, the findings here are consistent regarding the 

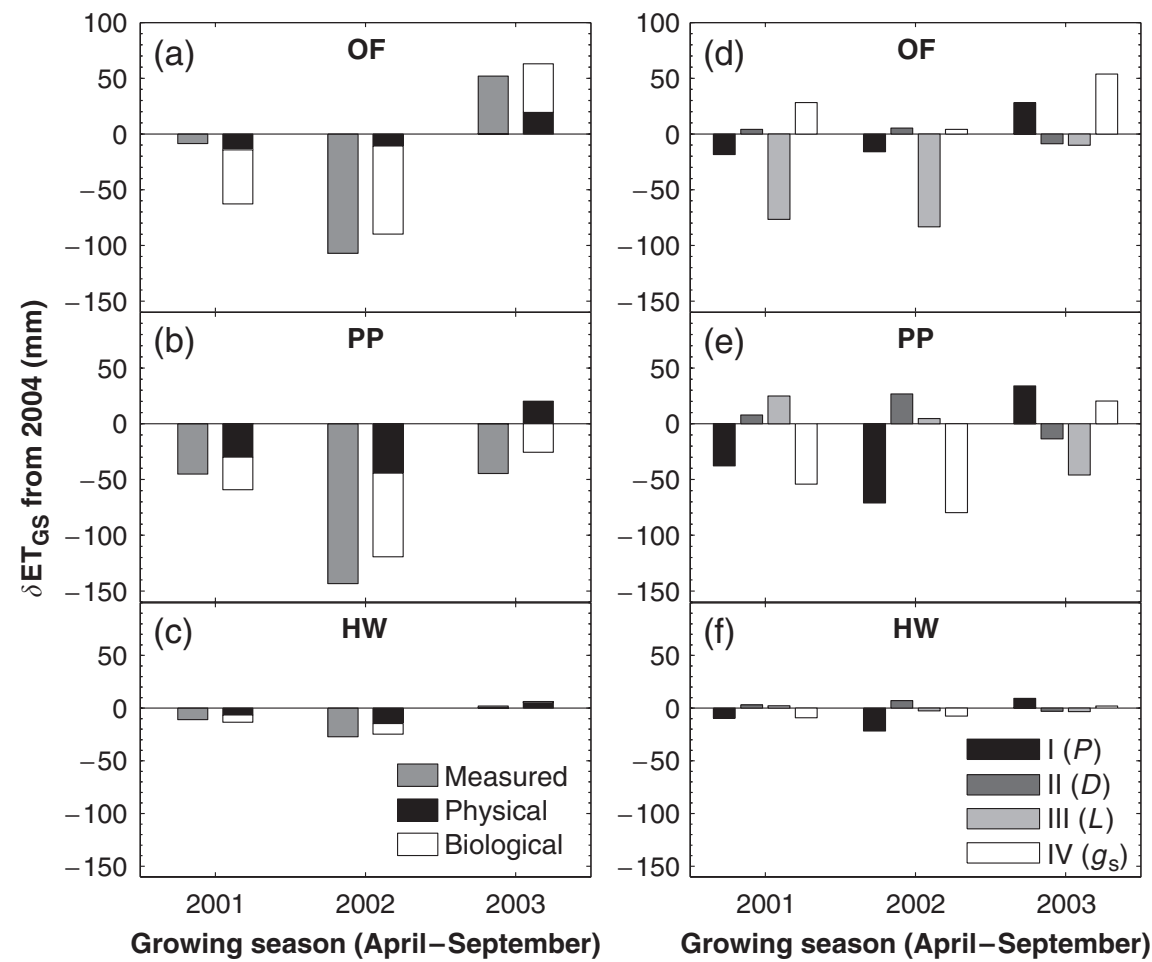

Fig. $9(\mathrm{a}-\mathrm{c})$ The contribution of physical [i.e. precipitation $(P)$ and vapor pressure deficit $(D)$ ] and biological [i.e. leaf area index $(L)$ and stomatal conductance $\left(g_{\mathrm{s}}\right)$ ] drivers to measured changes in April-September growing season evapotranspiration $\left(\delta \mathrm{ET}_{\mathrm{GS}}\right)$ at old field $(\mathrm{OF})$ planted pine (PP) and hardwood forest (HW) ecosystems in the Duke Forest, NC. (d-f) Same as (a-c) but for all physical and biological drivers separately.

assumption that rooting depth is approximately equal among ecosystems and is on the order of $35 \mathrm{~cm}$, but we cannot exclude the possibility that parts of HW may experience deep rooting.

With respect to the momentum flux $\left(\overline{u^{\prime} w^{\prime}}\right.$, i.e. $\left.-u_{*}^{2}\right)$, Fig. 3(c and e) suggests that much of its seasonal variability is primarily driven by the alterations in roughness density that vary with the drag coefficient and its dependence on the local Reynolds number (Poggi et al., 2004a, b), and the leaf area density distribution, rather than the variation in $L$ (Poggi et al., 2004a, b). In contrast, canopy wind speed $\left(u_{\mathrm{c}}\right.$, Fig. $\left.3 \mathrm{~d}\right)$ differed markedly among ecosystems and across seasons because of its strong dependence on $L$ (Table 2, Fig. 3e).

Despite large changes in surface albedo $\rho$ (data not shown) and surface temperature among ecosystems and across seasons, interecosystem differences in $R_{\mathrm{n}}$ were typically smaller than differences in $H$ and LE (Fig. 4a-c). Thus, if we separate the $R_{\mathrm{n}}$ into its shortwave $\left(1-\rho R_{\mathrm{i}, \mathrm{s}}\right)$ and longwave $\left(\sigma_{\mathrm{SB}}\left[\varepsilon_{\mathrm{a}} T_{\mathrm{a}}^{4}-\varepsilon_{\mathrm{s}} T_{\mathrm{s}}^{4}\right]\right)$ components, where $R_{\mathrm{i}, \mathrm{s}}$ is incident shortwave radiation, $\sigma_{\mathrm{SB}}$ is the Stephen-Boltzmann constant, and $\varepsilon_{\mathrm{a}}$ and $\varepsilon_{\mathrm{s}}$ are air and surface emissivity, respectively, we find that changes in $R_{\mathrm{n}}$ were dominated by changes in $R_{\mathrm{i}, \mathrm{s}}$, which was identical among ecosystems (Fig. 2b).

\section{Physical controls on ET}

The analysis of Eqn (4) in Fig. $9 d-f$ reveals the relative importance of $P_{\mathrm{GS}}, D_{\mathrm{GS}}, L_{\mathrm{GS}}$, and $g_{\mathrm{s}, \mathrm{GS}}$ on $\delta \mathrm{ET}_{\mathrm{GS}}$ at the GS time scale. All ecosystems were sensitive to changes in $P$, as expected from Fig. 7a. This response was particularly strong at PP (Fig. 9e) where approximately 40 and $70 \mathrm{~mm}$ of the observed $\delta \mathrm{ET}_{\mathrm{GS}}$ during 2001 and 2002, respectively, was due to low $P_{\mathrm{GS}}$. Interestingly, lower $P_{\mathrm{GS}}$ in 2001 and 2002 decreased $\mathrm{ET}_{\mathrm{GS}}$ by approximately equal amounts between 10 and $20 \mathrm{~mm}$ - at OF and HW (Fig. 9d and f). The increase in $\mathrm{ET}_{\mathrm{GS}}$ due to increased $P_{\mathrm{GS}}$ during 2003 was ca. $30 \mathrm{~mm}$ at $\mathrm{OF}$ and PP, and $10 \mathrm{~mm}$ at HW.

Changes in $\mathrm{ET}_{\mathrm{GS}}$ due to the direct impacts of $D_{\mathrm{GS}}$ were smaller in magnitude and of opposite sign than changes due to $P_{\mathrm{GS}}$ for all ecosystems and GSs, and were never larger than $25 \mathrm{~mm}$ (Fig. 9d-f). Thus, available water, rather than atmospheric demand, was the primary external control on $\delta \mathrm{ET}_{\mathrm{GS}}$ in the study ecosystems, although we note that the two are not independent; $P_{\mathrm{GS}}$ was lower and $D_{\mathrm{GS}}$ higher during drought. $\delta \mathrm{ET}_{\mathrm{GS}}$ due to $D_{\mathrm{GS}}$ was largest at PP for all GSs, as expected for the canopy with lowest mean $\Omega$ (Fig. $5 b$ ) and, thus, the strongest coupling of canopy response to atmospheric demand for water vapor. 
Biological controls on ET

The ecosystems differed strongly in their biological response to prevailing physical conditions. Dramatic reductions in $L_{\mathrm{GS}}$ at $\mathrm{OF}$ in response to drought reduced ET from 2004 levels by ca. $80 \mathrm{~mm}$ in 2001 and 2002. In contrast, differences in $L_{\mathrm{GS}}$ between 2004 and 2002 at PP, attributable to both drought and lagged recovery from ice storm damage in 2004 (McCarthy et al., 2006), changed $\mathrm{ET}_{\mathrm{GS}}$ by less than $10 \mathrm{~mm}$, but reductions in $L_{\mathrm{GS}}$ due to ice storm damage in 2003 decreased $\mathrm{ET}_{\mathrm{GS}}$ by $50 \mathrm{~mm}$. This decrease was nearly as strong as the reduction of $\mathrm{ET}_{\mathrm{GS}}$ due to decreased $P_{\mathrm{GS}}$ during drought. The compensatory effect of increased $g_{\text {s }}$ during low $L$ conditions during 2003 is consistent with progressive defoliation studies on P. taeda. Pataki et al. (1998b) used sapflux and porometry measurements to find that increased $g_{\text {s }}$ compensated completely for the physical removal of ca. $50 \%$ of $L$. $L_{\mathrm{GS}}$ varied little at HW among GSs and minimally impacted changes in $\mathrm{ET}_{\mathrm{GS}}$.

At PP, declines in $\mathrm{ET}_{\mathrm{GS}}$ due to $g_{\mathrm{s}}$, GS were slightly greater than those due to $P_{\mathrm{GS}}$ in both 2001 and 2002. In contrast, changes in $g_{\mathrm{s}, \mathrm{GS}}$ dominated the biological response of HW and was closely correlated to, but not as strong as, changes in $\mathrm{ET}_{\mathrm{GS}}$ due to $P_{\mathrm{GS}}$. If we take $P$ to be a surrogate of $\theta$, it is clear that PP is more sensitive to drought than HW. This result agrees with those from sap-flux scaled transpiration and mean canopy conductance at the same and similar ecosystems (Oren et al., 1998; Oren \& Pataki, 2001; Pataki \& Oren, 2003).

Nonlinear responses of $\mathrm{ET}_{\mathrm{GS}}$ to $P_{\mathrm{GS}}$ at $\mathrm{OF}$ can be attributed in part to vegetation death during the severe drought and a combination of mowing and cloudy conditions early in the 2004 GS. Maximum L at OF was not attained until later in the GS in 2004 in contrast to 2003, when OF was mowed later and was not accompanied by an uncharacteristic decrease in $\mathrm{ET}_{\mathrm{GS}}$. Mowing was found to affect the carbon balance and $L$ dynamics for a period of about 1 week at OF in 2001 (Novick et al., 2004), but it impacted $L$ and, thus, $\mathrm{ET}_{\mathrm{GS}}$ for longer time scales in 2004. Late growing season $\mathrm{ET}_{\mathrm{GS}}$ was similar at OF in 2003 and 2004, but the combination of mowing and cloudiness resulted in lower $\mathrm{ET}_{\mathrm{GS}}$ in the early 2004 GS (Figs 3a, 5c and 6a).

To summarize results from the linear perturbation analysis, low $L_{\mathrm{GS}}$ at $\mathrm{OF}$ decreased $\mathrm{ET}_{\mathrm{Gs}}$ during drought and high $g_{\mathrm{s}}$, Gs increased $\mathrm{ET}_{\mathrm{GS}}$ during wet conditions. The effect of the decrease in $L_{\mathrm{GS}}$ on $\mathrm{ET}_{\mathrm{GS}}$ was greater than the decrease due to $P_{\mathrm{GS}}$, indicating that the biological response to drought 'overcompensated' for the physical signal due to the drought sensitivity of the vegetation. PP was most sensitive to the external drivers $P_{\mathrm{GS}}$ and $D_{\mathrm{GS}}$ due to a combination of drought sensitivity and low $\Omega$ (Fig. 5b; Oren et al., 1998; Pataki \& Oren,
2003). The effect of the ice storm on $L_{\mathrm{GS}}$ (McCarthy et al., 2006) decreased $\mathrm{ET}_{\mathrm{GS}}$ to the same degree that high $P_{\mathrm{GS}}$ increased $\mathrm{ET}_{\mathrm{GS}}$ during the wet year. The biological response of $g_{\mathrm{s}, \mathrm{GS}}$ closely matched the changes in $P_{\mathrm{GS}}$ for all years. In contrast, $\mathrm{ET}_{\mathrm{GS}}$ at $\mathrm{HW}$ was relatively insensitive to the wide range of climatic and hydrologic conditions experienced during the measurement period.

\section{Comparison with other studies}

The finding that ET varied due to both biological and climatic responses among ecosystems and across years contains similarities and differences to the results of Gholz \& Clark (2002), who found that annual ET across a chronosequence of clear-cut, mid-rotation and fullrotation of slash pine plantations in Florida (FL) was more sensitive to climate than management activities (Table 6). Annual ET in the FL ecosystems was largely independent of plantation age, and the ratio ET $/ P$ was between $80 \%$ and $86 \%$ for most ecosystems and years except for a drought year in the mid-rotation stand, when it approached unity. This interaction follows logically from deep-rooted trees in a sandier soil; shallow-rooted post-clearcut vegetation could not access groundwater in the FL case.

ET averaged between 870 and $1170 \mathrm{~mm}$ in the FL study (Table 6), but only between 460 and $740 \mathrm{~mm}$ here despite the fact that $P$ was similar for the study periods (930-1350 $\mathrm{mm}$ in NC and $880-1390 \mathrm{~mm}$ in FL). Part of the ET differences can be explained by the lower temperatures (including more instances of subfreezing temperature), shorter GS, and lower available energy in NC. For example, given the relationships between LE and $R_{\mathrm{n}}$ reported by Gholz \& Clark (2002) and had their ecosystems experienced the same $R_{\mathrm{n}}$ as measured at PP, ET over the 4-year measurement period would have been $2680 \mathrm{~mm}$ at their mid-rotation plantation, almost exactly the same as what was measured at PP $(2650 \mathrm{~mm}$, Table 5). Along these lines, ET at HW varied from 580 to $640 \mathrm{~mm}$ (Table 5), very similar to 3 years of ET estimates at a hardwood forest (HW) at Oak Ridge, TN (with approximately the same latitude as our study sites) that also experienced drought (Table 6, 537-611 mm, Wilson \& Baldocchi, 2000). Interannual ET changes in the TN ecosystem were shown to be dominated by changes in canopy conductance. Hence, it is clear that ET in the SE is primarily driven by available energy, which is then modulated by other climatic and hydrologic constraints in which the differential sensitivities of the vegetation to climatic variability become important.

Estimated ET at OF for the period between April 11, 2001 and April 11, 2002 was $544 \mathrm{~mm}$, similar to the value estimated by Novick et al. (2004), who reported $568 \mathrm{~mm}$ (Table 6), noting that different gapfilling mod- 
Table 6 ET and T estimates from the study ecosystems, and ET estimates from Eddy-covariance measurements in other southeastern US (SE) ecosystems

\begin{tabular}{|c|c|c|c|c|c|c|}
\hline Study & Ecosystem & Time Period & ET & $\mathrm{ET}_{\mathrm{GS}}$ & $T$ & $T_{\mathrm{GS}}$ \\
\hline Novick et al. (2004) & OF & $\begin{array}{l}\text { April 11, } 2001 \\
\text { to April 11, } 2002\end{array}$ & 568 & & & \\
\hline \multirow{3}{*}{ Schäfer et al. (2002) } & \multirow[t]{3}{*}{ PP } & 1998 & 537 & & 519 & \\
\hline & & 1999 & 575 & & 533 & \\
\hline & & 2000 & 614 & & 519 & \\
\hline Pataki \& Oren (2003) & HW & 1997 & & & & 264 \\
\hline \multirow{2}{*}{$\begin{array}{l}\text { Emanuel et al. (2006, personal } \\
\text { communication) }\end{array}$} & \multirow{2}{*}{ Blandy Exp. Farm, VA } & 2001 & 572 & 445 & & \\
\hline & & 2002 & & 522 & & \\
\hline \multirow[t]{6}{*}{ Gholz \& Clark (2002) } & \multirow[t]{2}{*}{ Clearcut P. elliottii, FL } & 1998 & 1048 & & & \\
\hline & & 1999 & 869 & & & \\
\hline & \multirow[t]{2}{*}{ Mid-rotation P. elliottii, FL } & 1998 & 1014 & & & \\
\hline & & 1999 & 887 & & & \\
\hline & \multirow[t]{2}{*}{ Full rotation $P$. elliottii, FL } & 1996 & 1001 & & & \\
\hline & & 1997 & 1171 & & & \\
\hline \multirow[t]{3}{*}{ Wilson \& Baldocchi (2000) } & \multirow[t]{3}{*}{ Deciduous forest, Oak Ridge, TN } & 1995 & 537 & & & \\
\hline & & 1996 & 554 & & & \\
\hline & & 1997 & 611 & & & \\
\hline \multirow[t]{6}{*}{ Hanson et al. (2004) } & \multirow[t]{6}{*}{ Deciduous forest, Oak Ridge, TN } & 1995 & 515 & & & \\
\hline & & 1996 & 584 & & & \\
\hline & & 1997 & 624 & & & \\
\hline & & 1998 & 583 & & & \\
\hline & & 1999 & 658 & & & \\
\hline & & 2000 & 644 & & & \\
\hline
\end{tabular}

All flux units are in mm.

els were used. Novick et al. (2004) developed a model for $g_{c}$ similar to the Jarvis-type model described in Appendix B, then removed $\theta$ limitations on $g_{\mathrm{c}}$ to estimate the magnitude of ET that would have occurred in the absence of drought. This resulted in $738 \mathrm{~mm}$ of ET under drought-free conditions, over 13\% more than reported here for the wet year $(650 \mathrm{~mm}$, Table 5). The modeling approach and measurement period in Novick et al. (2004) required the assumption that physiological and $L$ dynamics remained unaltered, but $L$ changed over the full 4-year measurement period in a way that reduced ET below the expectations of the big leaf model that was parameterized for the 2001 mild-drought conditions. These results highlight the importance of studies designed to elucidate the long-term dynamics of compositionally and structurally dynamic ecosystems, but also suggest that reasonable predictions of ET can be obtained using simple modeling approaches with short-term data sets.

Comparative sapflux analyses on species that dominate the canopies at PP and HW agree with the findings here that PP is more coupled to atmospheric demand and is more drought sensitive. Estimates of $T$ at PP agree well with sapflux based estimates at the same forest for the period 1998-2000 (520-530 mm, Schäfer et al., 2002), and range from 400 to $560 \mathrm{~mm}$ except in the case of severe drought (Tables 5 and 6). In a chamber study of species common to PP and HW, T of the species that dominate the canopy at PP, P. taeda and the minor component $L$. styraciflua, showed greater sensitivity to increasing $D$ than Quercus phellos, a species common at HW (Pataki et al., 1998a). Of the three species, P. taeda had the largest cumulative soil water uptake, indicating the greatest potential for $T$ under well-watered conditions, and Q. phellos had the lowest $T$, similar to results here at the ecosystem scale.

At HW, sapflux in oak (Quercus alba and Q. rubra), hickory (Carya tomentosa), ash (Fraxinus americana), and sweetgum ( $L$. styraciflua) species was insensitive to $\theta$ depletion during a mild drought, only tulip poplar (L. tulipifera) showed a decrease in $T$ under water-limited conditions (Pataki \& Oren, 2003). Species sensitivity to hydrologic variability was similar between HW and structurally and compositionally similar stands elsewhere in Duke Forest (Oren \& Pataki, 2001), suggesting that results here may hold at larger spatial scales.

Potential impacts of land cover change on water resources

Agricultural and OF-type ecosystems have been continuously converted to PP-type ecosystems throughout the SE through ecosystem succession and anthropo- 
genic management since the reconstruction period following America's Civil War (Oosting, 1942; Wear \& Greis, 2002). Recent regional assessments have predicted that the landcover area of pine plantation ecosystems will continue to increase at the expense of agricultural and HW ecosystems (Wear \& Greis, 2002). $\mathrm{ET}$ at PP was greater than or equal to ET at OF and HW during all periods except severe drought (Table 5, Fig. 6) although some biases due to $I$ cannot be ignored (Appendix C). These results are consistent with the recent finding that plantation ecosystems often use more water than the ecosystems that they replace (Engel et al., 2005; Farley et al., 2005), but also suggest that efforts to reduce $I$, particularly the role of convection in creating $I$ (Fig. 10b), should be further explored.

The abandoned agricultural field and pine plantation 'early successional' ecosystems showed remarkably similar $H$ dynamics for all periods except during the winter and GS following the ice storm. The two canopies also showed similar behavior under severe drought; metrics of dryness through $\beta$ and $\Omega$ were nearly identical despite dramatically different canopy morphologies. The magnitude of $H$ dominates the development of the convective boundary layer with its critical influence on convective storm triggers. If $H$ is similar in these two ecosystem types for normal to dry precipitation conditions, this change in land cover may minimally impact some aspects of micro and mesoscale meteorology, primarily the statistics of convective precipitation (Juang et al., 2006), but higher LE at PP may tend to increase triggers of $P$ because the increase in water vapor concentration reduces the height of the lifting condensation level. The $H$ and $\beta$ dynamics of HW contrast those of both OF and PP (Figs 4 and 5), thus, the widespread conversion of HW

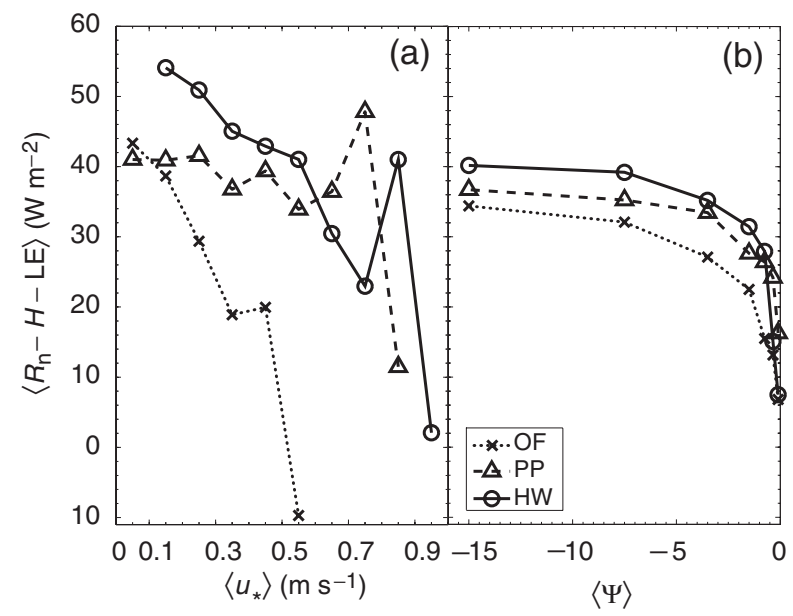

Fig. 10 Mean daily $(\langle\cdot\rangle)$ radiation balance closure for different $\left\langle u^{*}\right\rangle$ (a) and atmospheric stability $(\langle\Psi\rangle$, b) bins. to PP-type ecosystems (Wear \& Greis, 2002) may induce subtle influences on the summer-time convective precipitation. The comprehensive effects of plantation forestry on regional water cycling should be examined (Jackson et al., 2005), particularly in areas such as the SE where their contribution to land cover is large.

\section{Acknowledgments}

This research was supported by the Office of Science (BER), US Department of Energy, Grant No. DE-FG02-00ER63015, by the National Institute of Global Environmental Change (NIGEC) through the Southeast Regional Center at the University of Alabama, Tuscaloosa (DOE cooperative agreement DE-FC03090ER61010) and by the SERC-NIGEC RCIAP Research Program. Cup anemometer data was obtained under the US Department of Energy Contract No. DE-AC02-98CH10886 with Brookhaven National Laboratory. We would like to thank A. Porporato and R. Jackson for helpful comments on the manuscript, K. Novick, Y. Parashkevov, B. Poulter, K. Lewin, R. Nettles, G. Hon, and R. LaMorte for assistance with data collection in the Duke Forest, Judd Edeburn and the Office of the Duke Forest for logistical support, Y. Parashkevov and R. M. Broadwell for assistance in creating Fig. 1, and R. Emanuel, H. Epstein, C. Williams and J. Albertson for providing ET data from the Blandy Experimental Farm, VA.

\section{References}

Baldocchi D, Meyers T (1998) On using eco-physiological, micrometeorological and biogeochemical theory to evaluate carbon dioxide, water vapor and trace gas fluxes over vegetation: a perspective. Agricultural and Forest Meteorology, 90, 1-25.

Campbell GS, Norman JM (1998) An Introduction to Environmental Biophysics, 2nd edn. Springer, New York.

Cava D, Giostra U, Siqueira MBS et al. (2004) Organized motion and radiative perturbations in the nocturnal canopy sublayer above an even-aged pine forest. Boundary Layer Meteorology, 112, 129-157.

Detto M, Montaldo N, Albertson JD et al. (2006) Soil moisture and vegetation controls on evapotranspiration in a heterogeneous mediterranean ecosystem on Sardinia, Italy. Water Resources Research, 42, doi: 10.1029/2005WR004693/.

Ellsworth DS (2000) Seasonal $\mathrm{CO}_{2}$ assimilation and stomatal limitations in a Pinus taeda canopy. Tree Physiology, 20, 435-445.

Ellsworth DS, Oren R, Huang C et al. (1995) Leaf and canopy responses to elevated $\mathrm{CO}_{2}$ in a pine forest under free-air $\mathrm{CO}_{2}$ enrichment. Oecologia, 104, 139-146.

Emanuel RE, Albertson JD, Epstein HE et al. (2006) Carbon dioxide exchange and early old-field succession. Journal of Geophysical Research, 111, G01011.

Engel V, Jobbagy EG, Stieglitz M et al. (2005) Hydrological consequences of eucalyptus afforestation in the Argentine pampas. Water Resources Research, 41, W10409.

Falge E, Baldocchi D, Olson R et al. (2001) Gap filling strategies for long-term energy flux data sets. Agricultural and Forest Meteorology, 107, 71-77. 
Farley KA, Jobbagy EG, Jackson RB (2005) Effects of afforestation on water yield: a global synthesis with implications for policy. Global Change Biology, 11, 1565-1576.

Foley J, Costa M, Delire C et al. (2003) Green surprise? How terrestrial ecosystems could affect earth's climate. Frontiers in Ecology and the Environment, 1, 38-44.

Gholz HL, Clark KL (2002) Energy exchange across a chronosequence of slash pine forests in Florida. Agricultural and Forest Meteorology, 112, 87-102.

Goulden ML, Munger JW, Fan S et al. (1996) Measurements of carbon sequestration by long-term eddy covariance: methods and a critical evaluation of accuracy. Global Change Biology, 2, 169-182.

Hanson PJ, Amthor JS, Wullschleger SD et al. (2004) Oak forest carbon and water simulations: model intercomparisons and evaluations against independent data. Ecological Monographs, 74, 443-489.

Hendrey G, Ellsworth D, Lewin K et al. (1999) A free-air enrichment system for exposing tall forest vegetation to elevated atmospheric $\mathrm{CO}_{2}$. Global Change Biology, 5, 293-309.

Hoerling M, Kumar A (2003) The perfect ocean for drought. Science, 299, 691-694.

Hollinger DY, Richardson AD (2005) Uncertainty in eddy covariance measurements and its application to physiological models. Tree Physiology, 25, 873-885.

Houghton JT, Ding Y, Griggs DJ et al. (2001) Climate Change 2001: The Scientific Basis. THIRD Assessment Report of Working Group. Cambridge University Press, Cambridge.

Hsieh CI, Katul G, Chi T (2000) An approximate analytical model for footprint estimation of scalar fluxes in thermally stratified atmospheric flows. Advances in Water Resources, 23, 765-772.

Jackson RB, Jobbágy EG, Avissar R et al. (2005) Trading water for carbon with biological carbon sequestration. Science, $\mathbf{3 1 0}$ 1944-1947.

Jarvis PG (1976) The interpretation of the variations in leaf water potential and stomatal conductance found in canopies in the field. Philosophical Transactions of the Royal Society of London B, 273, 593-610.

Jarvis PG, McNaughton KG (1986) Stomatal control of transpiration: scaling up from leaf to region. Advances in Ecological Research, 15, 1-49.

Juang J-Y, Porporato A, Stoy PC et al. (2006) Hydrological and atmospheric controls on the statistics of convective precipitation events. Water Resources Research, in press.

Kaimal JC, Finnigan JJ (1994) Atmospheric Boundary Layer Flows: Their Structure and Measurements. Oxford University Press, Oxford.

Katul GG, Hsieh CI, Kuhn G et al. (1997) Turbulent eddy motion at the forest-atmosphere interface. Journal of Geophysical Research-Atmospheres, 102, 13409-13421.

Katul G, Leuning R, Oren R (2003) Relationship between plant hydraulic and biochemical properties derived from a steadystate coupled water and carbon transport model. Plant, Cell and Environment, 26, 339-350.

Katul GG, Mahrt L, Poggi D et al. (2004) One- and two-equation models for canopy turbulence. Boundary Layer Meteorology, 113, 81-109.
Katz RW, Brush GS, Parlange MB (2005) Statistics of extremes: modeling ecological disturbances. Ecology, 86, 1124-1134.

Lai C-T, Katul GG (2000) The dynamic role of root-water uptake in coupling potential to actual transpiration. Advances in Water Resources, 23, 427-439.

Loague K, Green RE (1991) Statistical and graphical methods for evaluating solute transport models: overview and applications. Journal of Contaminant Hydrology, 7, 51-73.

Luo YQ, Medlyn BE, Hui DF et al. (2001) Gross primary productivity in Duke Forest: modeling synthesis of $\mathrm{CO}_{2}$ experiment and eddy-flux data. Ecological Applications, 11, 239-252.

McCarthy HR, Oren R, Johnsen KH et al. (2006) Ice storms and management practices interact to affect current carbon sequestration in forests with potential mitigation under future $\mathrm{CO}_{2}$ atmosphere. Journal of Geophysical Research-Atmospheres, 111, D15103, doi: 10.1029/2005JD006428/.

McNulty SG (2002) Hurricane impacts on US forest carbon sequestration. Environmental Pollution, 116, S17-S24.

Meyer DG, Butler DG (1993) Statistical validation. Ecological Modelling, 68, 21-32.

Meyers TP (2001) A comparison of summertime water and $\mathrm{CO}_{2}$ fluxes over rangeland for well watered and drought conditions. Agricultural and Forest Meteorology, 106, 205-214.

Moncrieff JB, Mahli Y, Leuning R (1996) The propagation of errors in long-term measurements of land-atmosphere fluxes of carbon and water. Global Change Biology, 2, 231-240.

Norman JM, Campbell GS (1989) Canopy structure. In: Plant Physiological Ecology Field Methods and Instrumentation (eds Pearcy RW, Ehleringer JR, Mooney HA, Rundel PW), pp. 301-325. Chapman \& Hall, New York.

Novick KA, Stoy PC, Katul GG et al. (2004) Carbon dioxide and water vapor exchange in a warm temperate grassland. Oecologia, 138, 259-274.

Odum EP (1971) Fundamentals of Ecology. W. B. Saunders, Philadelphia.

Oosting HJ (1942) An ecological analysis of the plant communities of Piedmont, North Carolina. American Midland Naturalist, 28, 1-126.

Oren R, Ewers BE, Todd P et al. (1998) Water balance delineates the soil layer in which moisture affects canopy conductance. Ecological Applications, 8, 990-1002.

Oren R, Pataki DE (2001) Transpiration in response to variation in microclimate and soil moisture in southeastern deciduous forests. Oecologia, 127, 549-559.

Oren R, Sperry JS, Katul G et al. (1999) Survey and synthesis of intra- and interspecific variation in stomatal sensitivity to vapor pressure deficit. Plant, Cell and Environment, 22, 1515-1526.

Palmroth S, Maier CA, McCarthy HR et al. (2005) Contrasting responses to drought of the forest floor $\mathrm{CO}_{2}$ efflux in a loblolly pine plantation and a nearby oak-hickory forest. Global Change Biology, 11, 421-434.

Pataki DE, Oren R (2003) Species differences in stomatal control of water loss at the canopy scale in a mature bottomland deciduous forest. Advances in Water Resources, 26, 1267-1278.

Pataki DE, Oren R, Katul GG et al. (1998a) Canopy conductance of Pinus taeda, Liquidambar styraciflua and Quercus phellos under 
varying atmospheric and soil water conditions. Tree Physiology, 18, 307-315.

Pataki DE, Oren R, Phillips N (1998b) Responses of sap flux and stomatal conductance of Pinus taeda L. Trees to stepwise reductions in leaf area. Journal of Experimental Botany, 49, 871-878

Peters AJ, Ji L, Walter-Shea E (2003) Southeastern US vegetation response to ENSO events (1989-1999). Climatic Change, 60, 175-188.

Pielke RA, Avissar R, Raupach M et al. (1998) Interactions between the atmosphere and terrestrial ecosystems: influence on weather and climate. Global Change Biology, 4, 461-475.

Poggi D, Katul GG, Albertson JD (2004a) Momentum transfer and turbulent kinetic energy budgets within a dense model canopy. Boundary Layer Meteorology, 111, 589-614.

Poggi D, Porporato A, Ridolfi L et al. (2004b) The effect of vegetation density on canopy sub-layer turbulence. Boundary Layer Meteorology, 111, 565-587.

Porporato A, D'Odorico P, Laio F et al. (2002) Ecohydrology of water-controlled ecosystems. Advances in Water Resources, 25, 1335-1348.

Ramos da Silva R, Bohrer G, Werth D et al. (2006) Sensitivity of ice storms in the southeast US to Atlantic SST - insights from a case study of the December 2002 storm. Monthly Weather Review, 134, 1454-1464.

Richardson AD, Hollinger DY, Burba GG et al. (2006) A multi-site analysis of uncertainty in tower-based measurements of carbon and energy fluxes. Agricultural and Forest Meteorology, 136, 1-18.

Roberts J (1983) Forest transpiration: a conservative hydrological process? Journal of Hydrology, 66, 133-141.

Schäfer KVR, Oren R, Lai CT et al. (2002) Hydrologic balance in an intact temperate forest ecosystem under ambient and elevated atmospheric $\mathrm{CO}_{2}$ concentration. Global Change Biology, 8, 895-911.

Stoy PC, Katul GG, Siqueira MBS et al. (2005) Variability in net ecosystem exchange from hourly to inter-annual time scales at adjacent pine and hardwood forests: a wavelet analysis. Tree Physiology, 25, 887-902.

Wear DN, Greis JG (2002) The southern forest resource assessment summary report. In: Southern Forest Resource Assessment. Gen. Tech. Rep. SRS-53. (eds Wear DN, Greis JG), US Department of Agriculture, Forest Service, Southern Research Station, Asheville, NC.

Webb EK, Pearman GI, Leuning R (1980) Correction of flux measurements for density effects due to heat and water vapour transfer. Quarterly Journal of the Royal Meteorological Society, 106, 85-100.

Wilson KB, Baldocchi DD (2000) Seasonal and interannual variability of energy fluxes over a broadleaved temperate deciduous forest in North America. Agricultural and Forest Meteorology, 100, 1-18.

Wilson KB, Baldocchi DD, Hanson PJ (2001) Leaf age affects the seasonal pattern of photosynthetic capacity and net ecosystem exchange of carbon in a deciduous forest. Plant, Cell and Environment, 24, 571-583.
Wilson KB, Goldstein A, Falge E et al. (2002) Energy balance closure at FLUXNET sites. Agricultural and Forest Meteorology, 113, 223-243.

Wilson KB, Meyers TP (2001) The spatial variability of energy and carbon dioxide fluxes at the floor of a deciduous forest. Boundary-Layer Meteorology, 98, 443-473.

Xie L, Pietrafesa LJ, Wu KJ (2002) Interannual and decadal variability of landfalling tropical cyclones in the southeast coastal states of the United States. Advances in Atmospheric Sciences, 19, 677-686.

Xie L, Yan TZ, Pietrafesa L (2005) The effect of Atlantic sea surface temperature dipole mode on hurricanes: implications for the 2004 Atlantic hurricane season. Geophysical Research Letters, 32, L03701, doi: 10.1029/2004GL021702/.

\section{Appendix A: separating evaporation from transpiration using simplified models and EC measurements}

Transpiration is not measured directly by the EC system, which measures entire ecosystem fluxes, but estimates are desirable for ecosystem intercomparisons and to elucidate canopy physiology. We used a simple radiation transfer model (Campbell \& Norman, 1998) to separate $E$ from $T$ and, thus, $g_{c}$, and estimated an average $g_{\mathrm{s}}$ for all leaves in the canopy by dividing $g_{\mathrm{c}}$ by $L$ [Eqn (B2)]. The model uses an exponential radiation extinction model after Beer's Law

$$
\tau(\psi)=\exp \left[-\sqrt{\alpha_{\text {leaf }}} K(\psi) P A I \Omega_{\mathrm{c}}\right],
$$

where $\psi$ is zenith angle, $\alpha_{\text {leaf }}$ is leaf absorptivity taken to average 0.5 across the photosynthetically active and near infrared bands (Campbell \& Norman, 1998), PAI is plant area index (i.e. the sum of LAI and stem area) and $\Omega_{\mathrm{c}}$ is a leaf clumping factor taken to be 1 at OF (i.e. leaves are randomly distributed), 0.6 at PP, and 0.84 at HW after HW measurements at Oak Ridge, TN (Baldocchi \& Meyers, 1998). $K$ is the extinction coefficient for an ellipsoidal leaf distribution

$$
K(\psi)=\frac{\sqrt{x^{2}+\tan ^{2} \psi}}{x+1.774(x+1.182)^{-0.733}},
$$

where $x$ is the ratio of horizontal vs. vertical canopy projected area, taken to be 0.7 at OF (Novick et al., 2004), 1.64 at PP (Luo et al., 2001), and 1 at HW. The relationship between radiation that penetrates that canopy when the canopy is inactive (i.e. when $L$ is near 0 at $\mathrm{OF}$ and $\mathrm{HW}$, and when $T_{\mathrm{a}}$ is less than $10^{\circ} \mathrm{C}$ at $\mathrm{PP}$ ) and measured LE is used to model $E$. $T$ was determined by subtracting modeled $E$ from measured $E T$. We note that such an analysis is not intended to replace rigorous analyses of water balance at the plot level, rather it is intended to provide a method for acquiring variables of ecological interest from EC-measured ET. 


\section{Appendix B: PM equation and models for water vapor and heat conductance}

The PM equation, after taking into account $I$ (Wilson \& Baldocchi, 2000) is

$$
\mathrm{LE}=\lambda g_{\mathrm{v}} S\left(\frac{R_{\mathrm{n}}-G-I-\lambda g_{\mathrm{v}} D / p_{\mathrm{a}}}{\lambda g_{\mathrm{v}} S+c_{p} g_{\mathrm{H}}}\right)+\frac{\lambda g_{\mathrm{v}} D}{p_{\mathrm{a}}},
$$

$g_{\mathrm{v}}$ and $g_{\mathrm{H}}$ require modeling. $g_{\mathrm{c}}$ can be defined as

$$
g_{\mathrm{c}}=g_{\mathrm{s}}, L,
$$

where $g_{\mathrm{s}}$ is stomatal conductance modeled after Jarvis (1976) and modified by Oren et al. (1999) for stomatal sensitivity to $D$

$$
g_{\mathrm{s}}=\left(a_{\mathrm{P}} \mathrm{PAR}+b_{\mathrm{P}}\right)(1-m \log [D]),
$$

$m$ takes a theoretical value of 0.5-0.6 (Oren et al., 1999).

Conductance at the leaf boundary layer $\left(g_{\mathrm{b}}\right)$ is a combination of forced convection and free convection owing to the temperature difference between leaf and surrounding air. Forced convection can be considered dominant if the ratio between the Grashof number $(\mathrm{Gr}$, the ratio of buoyant and inertial forces to squared viscous force, $\mathrm{Gr}=a d^{3}\left(T_{\mathrm{c}}-T_{\mathrm{a}}\right) / T_{\mathrm{k}} v^{2}$, where $a$ is acceleration due to gravity, $T_{\mathrm{k}}$ is $T_{\mathrm{a}}$ in degrees Kelvin, $v$ is the kinematic viscosity and $d$ is the characteristic length scale of the leaves) and squared Reynolds number (Re, the ratio between inertial and viscous forces, $\left.\operatorname{Re}=u_{\mathrm{c}} d / v\right)$ is small. $d$ for typical P. taeda needles was estimated using leaf width measurements to be $0.75 \mathrm{~mm}$ (Campbell \& Norman, 1998). Using leaf temperature measurements from an infrared temperature sensor (Model 4000, Everest Interscience, Tuscon, AZ, USA) during the day during a typical summer period (May 2004), Gr/Re averaged less than 0.01 . Thus, we can simplify $g_{\mathrm{b}}$ to both sensible heat $\left(g_{\mathrm{Hb}}\right)$ and latent heat $\left(g_{\mathrm{vb}}\right)$ by considering only the forced convection case which, when using typical values, the thermal diffusivity and density of air (Campbell \& Norman, 1998) equal

$$
g_{\mathrm{Hb}}=0.135 \sqrt{\frac{u_{\mathrm{c}}}{d}} L, \quad g_{\mathrm{vb}}=0.147 \sqrt{\frac{u_{\mathrm{c}}}{d}} L,
$$

where $g_{\mathrm{Hb}}$ is boundary layer conductance to sensible heat, $g_{\mathrm{vb}}$ is boundary layer conductance to water vapor, and $u_{\mathrm{c}}$ is canopy wind speed, the estimation of which is described below.

Atmospheric conductance to sensible heat $\left(g_{\mathrm{Ha}}\right)$ and water vapor $\left(g_{\mathrm{va}}\right)$ in the turbulent surface layer are equal

$$
g_{\mathrm{Ha}}=g_{\mathrm{va}}=\frac{k \hat{\rho} u_{*}}{\left[\ln \left(\frac{z-d}{z_{\mathrm{H}}}\right)+\Psi_{\mathrm{H}}\right]},
$$

where $k$ is the von Karman constant $(=0.4)$ and $z_{\mathrm{H}}$ is roughness lengths for heat (Campbell \& Norman, 1998).
The nonlinear atmospheric stability term $\left(\Psi_{\mathrm{H}}\right)$ tends to 0 for neutral conditions.

$g_{c}$ [i.e. $g_{s} L$, Eqn (B2)] is approximately an order of magnitude less than $g_{\mathrm{va}}$ and $g_{\mathrm{vb}}$ for the forested ecosystems and twice as large as $g_{\mathrm{va}}$ and $g_{\mathrm{vb}}$ at OF. However, $g_{\mathrm{Hb}}$ and $g_{\mathrm{Ha}}$ are roughly equal and depend on two different terms related to the wind speed, $u_{\mathrm{c}}$ and $u_{*}$ respectively. Thus, for the purposes of PM model differentiation (Appendix D), $g_{\mathrm{v}}$ was simplified as $g_{c}$, but for flux gapfilling the series conductance $g_{\mathrm{v}}=g_{\mathrm{va}} g_{\mathrm{vb}} g_{\mathrm{vc}} /\left(g_{\mathrm{va}} g_{\mathrm{vb}}+g_{\mathrm{va}} g_{\mathrm{vc}}+g_{\mathrm{vb}} g_{\mathrm{vc}}\right)$, was used. $g_{\mathrm{H}}$ was taken to be the series combination of $g_{\mathrm{Ha}}$ and $g_{\mathrm{Hb}}$ for both flux gapfilling and PM model differentiation, $g_{\mathrm{H}}=g_{\mathrm{Ha}} g_{\mathrm{Hb}} /\left(g_{\mathrm{Ha}}+g_{\mathrm{Hb}}\right)$.

\section{Canopy mean wind speed model}

$u_{\mathrm{c}}$ was modeled for different canopies using firstorder closure principles assuming a constant mixing length ( $l$ ) inside the canopy as described in (Katul et al., 2004), who found that first-order closure models match measured values as well as higher-order models if $l$ is a priori specified. Using first-order closure principles, the turbulent diffusion coefficient $\left(K_{\mathrm{m}}\right)$ is modeled as

$$
K_{\mathrm{m}}=l^{2}\left|\frac{\partial \bar{u}}{\partial z}\right|,
$$

the momentum flux is modeled as

$$
\overline{u^{\prime} w^{\prime}}=-K_{\mathrm{m}} \frac{\partial \bar{u}}{\partial z},
$$

and the mean momentum budget is given by

$$
\frac{\partial \overline{u^{\prime} w^{\prime}}}{\partial z}=-C_{d} \operatorname{PAD}(z) \bar{u}^{2},
$$

where $C_{d}$ is the drag coefficient assumed constant at 0.2, $\overline{u^{\prime} w^{\prime}}$ is the momentum flux (equal to $u_{*}^{2}$ at the top of the canopy) and measured $u$ is a specified upper boundary condition. $l$ is specified as $0.2 h, z$ is height. The system of Eqns (B6)-(B8) has three unknowns $\left(\overline{u^{\prime} w^{\prime}}, K_{t}\right.$ and $\left.\bar{u}\right)$ and can be readily solved using standard numerical procedures. An appropriately weighted $u_{\mathrm{c}}$ is obtained by multiplying the $u$ profile obtained from (B7)-(B8) by normalized PAD.

\section{Appendix C: an analysis of radiation balance closure}

Plausible reasons for the observed lack of energy balance closure at FLUXNET sites (e.g. Wilson et al., 2002) include footprint differences between radiometers and EC-measured fluxes, instrument bias, neglected storage sinks, high frequency losses, and advection. These explanations can be sequentially negated, but the latter is more complicated. The differing foot- 
prints will not produce a consistent sign in $I$. We found good agreement between Q7 and Kipp and Zonen radiometers (biases rarely exceeded 5\%) and the EC systems at PP and HW matched results from the Ameriflux roving system. Storage fluxes average nearly 0 at the daily time step. Flux-transporting eddy sizes are comparable with $h$ in the forested ecosystems (far exceeding instrument separation), thus minimizing high-frequency losses. The night-time $\Psi$ filter is meant to reduce potential advection, but does not ensure that the role of advection-type events are isolated.

We find a relationship between $I$ and $u_{*}$ (Fig. 10a), as found in other studies (Wilson et al., 2002) suggesting that either a lack of turbulent transport or diminished role of turbulent transport (or both) are responsible for the magnitude of $I$. At the diurnal time step, $I$ was clearly related to $\Psi$ and increased during unstable conditions when convection dominates turbulent transport (Fig. 10b). If convective cells form, EC measurements may effectively sample both the biosphereatmosphere interface, as well as entrainment from the top of the atmospheric boundary layer. These mesoscale atmospheric events act on a time scale longer than the typical $\frac{1}{2}$ hour EC averaging period, consistent with the notion that low-frequency events are the largest contributors to $I$.

The top of the boundary layer will be relatively dry at times (which would decrease measured LE), but it will almost certainly be colder than the surface layer. Accordingly, one might expect EC-measured $H$ to depart more from the true surface flux than LE if convection explains the bulk of $I$ as hypothesized. Also, $H$ is an active scalar that impacts the buoyant production of TKE and its estimation may be more impacted by convection. However, there is no consistent way to test for the specific effects of convective transport given our measurements and there is no agreement within the FLUXNET community regarding how or if corrections should be made to account for $I$. Future research should investigate any relationships between the state of the entrainment zone and $I$.

When interpreting our results, the true surface flux of $H+$ LE may be 20-30\% higher than EC measurements (the magnitude of $I$ ), but it is likely that the underestimation in LE is less than 1/2 of $I$ and lower than $10-15 \%$ if the top of the boundary layer may be relatively wet or dry but is consistently cold. (Additional support for this argument is the good agreement between sapflux and EC measurements during dry periods as found at PP.) Also, the length scale of the convective cells is on the order of the boundary layer height (here commonly $1000 \mathrm{~m}$; Juang et al., 2006) and any effects would impact our measurements equally because towers are separated by only $750 \mathrm{~m}$. Thus, when comparing ecosystems the difference - not the magnitude - of $I$ among sites may be a better indicator of potential bias. This difference does not exceed 13\%, so any comparative bias in ET is likely less than $6.5 \%$. Bias in $\beta$, a minor component of this study, may be higher.

\section{Appendix D: perturbation analysis using the PM equation}

The total derivative of the PM Eqn (B1) is:

$$
\begin{aligned}
\mathrm{dET}= & \frac{\partial \mathrm{ET}}{\partial R_{\mathrm{n}}} \mathrm{d} R_{\mathrm{n}}+\frac{\partial \mathrm{ET}}{\partial D_{\mathrm{II}}} \mathrm{d} D+\frac{\partial \mathrm{ET}}{\partial S_{\mathrm{III}}} \mathrm{d} S \\
& +\frac{\partial \mathrm{ET}}{\partial g_{\mathrm{H}}} \mathrm{d} g_{\mathrm{H}}+\frac{\partial \mathrm{ET}}{\partial L_{\mathrm{V}}} \mathrm{d} L+\frac{\partial \mathrm{ET}}{\partial g_{\mathrm{V}}} \mathrm{d}_{\mathrm{V}},
\end{aligned}
$$

and the corresponding partial derivatives are:

$$
\begin{gathered}
\frac{\partial \mathrm{ET}}{\partial R_{\mathrm{n}}}=\frac{\lambda g_{\mathrm{s}} L S}{c_{p} g_{\mathrm{H}}+\lambda g_{\mathrm{s}} L S}, \\
\frac{\partial \mathrm{ET}}{\partial D}=\frac{\lambda g_{\mathrm{s}} L}{p_{\mathrm{a}}}, \\
\frac{\partial \mathrm{ET}}{\partial S}=-\frac{\lambda c_{p} g_{\mathrm{H}} g_{\mathrm{s}} L\left(\lambda g_{\mathrm{s}} L+p_{\mathrm{a}}\left[G-I-R_{\mathrm{n}}\right]\right)}{p_{\mathrm{a}}\left(c_{p} g_{\mathrm{H}}+\lambda g_{\mathrm{s}} L S\right)^{2}}, \\
\frac{\partial \mathrm{ET}}{\partial g_{\mathrm{H}}}=\frac{\lambda c_{p} g_{\mathrm{s}} L S\left(\lambda g_{\mathrm{s}} L+p_{\mathrm{a}}\left[G-I-R_{\mathrm{n}}\right]\right)}{p_{a}\left(c_{p} g_{\mathrm{H}}+\lambda g_{\mathrm{s}} L S\right)^{2}},
\end{gathered}
$$

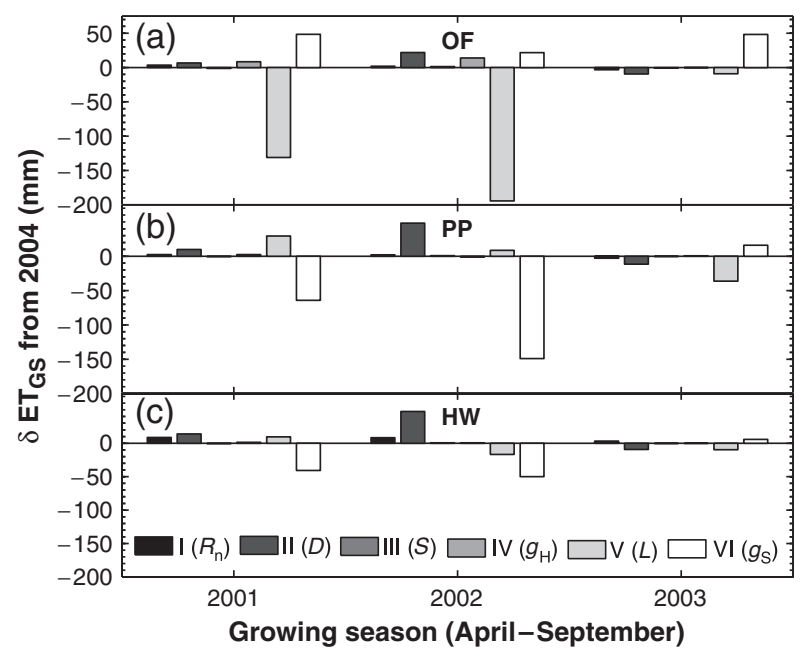

Fig. 11 Same as Fig. 9d-f but for the change in growing season ET $\left(\delta \mathrm{ET}_{\mathrm{GS}}\right)$ attributable to each term of the Penman-Monteith Eqn (B1) for old field (OF, a), pine plantation (PP, b) and hardwood forest (HW, c) ecosystems. 
$\frac{\partial \mathrm{ET}}{\partial L}=\frac{\left(\lambda g_{s}\left[c_{p} g_{\mathrm{H}} S\left(-p_{\mathrm{a}}\left[G-I-R_{\mathrm{n}}\right]+2 g_{s} L[D-1]\right)+\lambda^{2} g_{\mathrm{s}}^{2} L^{2} S^{2}[D-1]+c_{p}^{2} g_{\mathrm{H}}^{2} D\right]\right)}{p_{\mathrm{a}}\left(c_{p} g_{\mathrm{H}}+\lambda g_{s} L S\right)^{2}}$,

$\frac{\partial \mathrm{ET}}{\partial g_{\mathrm{s}}}=\frac{\left(\lambda L\left[c_{p} g_{\mathrm{H}} S\left(-p_{\mathrm{a}}\left[G-I-R_{\mathrm{n}}\right]+2 g_{\mathrm{s}} L[D-1]\right)+\lambda^{2} g_{\mathrm{s}}^{2} L^{2} S^{2}[D-1]+c_{p}^{2} g_{\mathrm{H}}^{2} D\right]\right)}{p_{\mathrm{a}}\left(c_{p} g_{\mathrm{H}}+\lambda g_{\mathrm{s}} L S\right)^{2}}$.

The analysis of (D1)-(D7) at the GS time scale gave similar results to the linear model with some differences due to averaging terms of the PM [Eqn (B1)] at the GS time scale (Figs 9 and 11). Changes in $R_{n}, S$ (related to $T_{\mathrm{a}}$ ) and $g_{\mathrm{H}}$ between GSs changed $\mathrm{ET}_{\mathrm{GS}}$ by less than $D, L$, and $g_{\mathrm{s}}$ when considering all ecosystems and all years (Fig. 11). However, changes in $R_{\mathrm{n}}, S$ and $g_{\mathrm{H}}$ changed ET to a similar degree as $D$ at OF in years without severe drought. These drivers were more important (but minor) contributors to $\delta \mathrm{ET}_{\mathrm{GS}}$ than $L_{\mathrm{GS}}$ at HW, because $L_{\mathrm{GS}}$ changed minimally among years. Thus, to a first order, the linear perturbation analysis captured the dominant drivers of ET change at the GS time scale. Undertaking a more rigorous analysis with the PM model did not alter results. 